Center for

Mathematical Economics

Working Papers

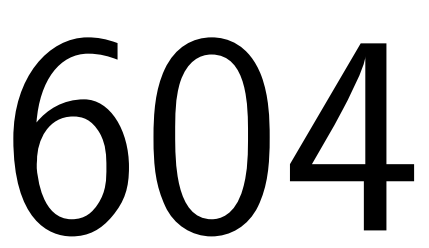

December 2018

Expectation Formation and Learning in the Labour Market with On-the-Job Search and Nash Bargaining

Erdenebulgan Damdinsuren and Anna Zaharieva

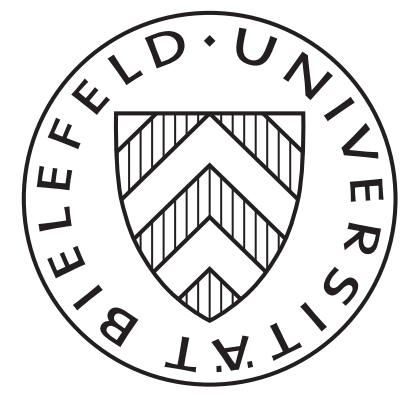




\title{
Expectation Formation and Learning in the Labour Market with On-the-Job Search and Nash Bargaining*
}

\author{
Erdenebulgan Damdinsuren†, Anna Zaharieva ${ }^{\ddagger}$
}

December 14, 2018

\begin{abstract}
This paper develops a search and matching model with heterogeneous firms, on-the-job search by workers, Nash bargaining over wages and adaptive learning. We assume that workers are boundedly rational in the sense that they do not have perfect foresight about the outcome of wage bargaining. Instead workers use a recursive OLS learning mechanism and base their forecasts on the linear wage regression with the firm's productivity and worker's current wage as regressors. For a restricted set of parameters we show analytically that the Nash bargaining solution in this setting is unique. We embed this solution into the agentbased simulation and provide a numerical characterization of the Restricted Perceptions Equilibrium. The simulation allows us to collect data on productivities and wages which is used for updating workers' expectations. The estimated regression coefficient on productivity is always higher than the bargaining power of workers, but the difference between the two is decreasing as the bargaining power becomes larger and vanishes when workers are paid their full productivity. In the equilibrium a higher bargaining power is associated with higher wages and larger wage dispersion, in addition, the earnings distribution becomes more skewed. Moreover, our results indicate that a higher bargaining power is associated with a lower overall frequency of job-to-job transitions and a lower fraction of inefficient transitions among them. Our results are robust to the shifts of the productivity distribution.
\end{abstract}

JEL classification: C63, D83, J31, J63, J64

Keywords: On-the-job search, Nash bargaining, OLS learning, inefficient transitions

${ }^{*}$ We would like to thank Volker Böhm, Herbert Dawid, Pietro Dindo, Seppo Honkapohja and Mauro Napoletano for their helpful comments and suggestions.

${ }^{\dagger}$ E-mail: edamdinsuren@uni-bielefeld.de Tel.: +49-521-106-4864, Bielefeld Graduate School of Economics and Business, Bielefeld University, 33615 Bielefeld, Germany; Department of Economics and Finance, Catholic University, 20123 Milan, Italy. E. Damdinsuren acknowledges financial support of EXSIDE, project 8

${ }^{\ddagger}$ E-mail: azaharieva@wiwi.uni-bielefeld.de Tel.: +49-521-106-5637, Fax: +49-521-106-89005, Center for Mathematical Economics and Department of Business Administration and Economics, Bielefeld University, 33501 Bielefeld, Germany 


\section{Introduction}

Classical search and matching studies often view the matching function as a "black box" meaning that neither workers nor firms are fully informed about the underlying matching process. In contrast, most studies make an assumption that workers can perfectly foresee the outcomes of future wage negotiations with heterogeneous employers. In a setting with job-to-job mobility and bargained wages this framework requires extreme assumptions concerning workers' knowledge and computing abilities, moreover, it renders the model analytically intractable. Several studies have modified the framework by allowing for permanent wage renegotiations and counteroffers among competing employers to arrive at the analytical solution ${ }^{1}$. Even though it is a realistic assumption for academic positions and senior management jobs, counteroffers from competing employers are rare in many other professions and occupations. In this paper we follow a different approach by considering boundedly rational workers and model the bargaining process as a "black box" meaning that workers have limited foresight and can not perfectly predict the outcome of wage bargaining. In particular, we follow the approach summarized in Hommes (2013) and Evans and Honkapohja (2001) and characterize a Restricted Perceptions Equilibrium where workers use adaptive learning mechanisms and base their forecasts on time series data. Thus workers in our model behave as economic statisticians and update their beliefs over time as new data becomes available. In the steady state some workers are overoptimistic about their situation and disappointed by the low wage. Other workers are pessimistic in the beginning and positively surprised by the successful outcome of bargaining. Nevertheless, the expectations of workers are "self-confirming" in the equilibrium in the sense that the data that workers observe lead them to take actions that reproduce the data they observe.

More specifically, we assume that workers are forward-looking and form linear expectations about future wages. Thus workers correctly expect to bargain a higher wage if matched with a more productive employer. Also workers with higher current wages correctly anticipate to bargain a higher wage with a new employer. Nevertheless, workers can not perfectly foresee the non-linearity of the Nash bargaining process and form their expectations based on the estimated linear regression with the employer's productivity and worker's current wage as regressors. The estimated regression coefficients are based on aggregate statistical data up to the current period of time. Inline with some empirical evidence (e.g. Gaffeo et al. (2003)) we assume that the distribution of firm types has decreasing density, moreover, firms always bargain over the wage with new employees but don't renegotiate wages after the contract is signed. In this setting we are able to derive the analytical expressions for the value functions of workers and firms, this yields an implicit analytical solution for the Nash bargaining problem. For a restricted set of parameters, we can show that the bargaining solution is unique and the actual wage is increasing in the employer's productivity and the current wage of the worker. We show numerically that these properties hold for a wider range of parameters.

Further, we embed the analytical Nash bargaining solution in the agent-based simulation of the labour market. The agent-based simulation approach is widely used for the analysis of learning mechanisms in dynamic models especially in settings with heterogeneous agents and complex interactions between them. For a summary see Neugart and Richiardi (2018), Dawid

\footnotetext{
${ }^{1}$ Postel-Vinay and Robin (2002a, 2002b), Cahuc et al. (2006)
} 
and Delli Gatti (2018) and Delli Gatti et al. (2018). To the best of our knowledge it was not used so far for the analysis of workers' expectation formation in the labour market with search frictions, even though the advantages of this approach for the analysis of labour markets have been emphasized by Freeman already in 1998. More specifically, we use the simulation to record workers' transitions across different employers and record their wages and productivities. This statistical data base is used by workers in every period of time to form and update their wage expectations. Comparing expected and actual wages in the steady state we can show that workers are positively or negatively surprised by the bargained wage but the overall quality of forecasting is very high and it is increasing in the bargaining power of workers. The reason is that even though the actual bargained wage is not linear in productivity and the current wage, its curvature in both variables is relatively low. The slope coefficient on productivity in the linear regression is always higher than the bargaining power parameter, but the difference between the two is decreasing with the bargaining power and falls down to zero when workers are paid their full productivity. This is the limiting case when workers' expectations are rational.

Considering the key macroeconomic properties of the model, we can show that the steadystate wage distribution is unimodal and positively skewed inline with the empirical evidence ${ }^{2}$. Even though we assume that firm types/productivities have decreasing density, workers move up in the productivity ladder by changing employers. However, climbing the ladder becomes more difficult the higher the wage of the worker, since productivity realizations above the current wage become more and more scarce. Thus the majority of workers climbs quickly to the middle range of the wage distribution where the speed of climbing slows down. Further, we can show that the average wage in the steady-state is increasing in the bargaining power of workers and there is a gradual shift towards the analytical wage distribution in the limiting case when workers are paid their full productivity. At the same time wages become more dispersed and the positive skewness of the wage distribution becomes stronger with a higher bargaining power.

One of the most important properties of our model is that it allows to evaluate the extent of inefficient transitions. Even though workers' job changes are always efficient from the individual perspective as workers only change the job if they get a higher wage, some transitions are socially inefficient since workers are moving from more productive employers to less productive ones. Intuitively, for any interior bargaining power there is a gap between the output produced by the worker and his/her wage. If the new employer's productivity falls within this gap a socially inefficient transition takes place. Our results indicate that a higher bargaining power of workers is associated with a lower overall frequency of job-to-job transitions and a lower fraction of inefficient transitions among them. This sheds some light on the lower job-to-job mobility of workers in countries with strong unionization, like France and Germany, and more intensive job-to-job mobility in countries with weak unions, like the US and UK, reported in Jolivet et al. (2006). There is only one other study that investigated the extent of inefficient transitions, this is Flinn et al. (2017). However, their model requires a simultaneous presence of firms with two different wage strategies - those who post and never negotiate over wages and those who always negotiate and match outside offers. In this respect our setting is less restrictive since inefficient transitions take place even if all firms follow the same strategy.

Finally, we show that our results are robust to the shifts of the productivity distribution.

\footnotetext{
${ }^{2}$ Neal and Rosen (2000), Mortensen (2003) and Christensen et al. (2005)
} 
In particular, we find that the coefficients of the linear regression used in shaping workers' expectations do not change if the average productivity of firms is increased or reduced. This change has a nominal character, so the relative properties of the model, such as the frequency of job-to-job transitions, the fraction of inefficient transitions and the slope of the wage regression don't change. Even though this finding is not straightforward it is consistent with the result by Hornstein et al. (2011). This study reports that the ratio between the mean and the minimum wage as well as the fraction of job-to-job movers in the standard on-the-job search model by Burdett and Mortensen (1998) doesn't depend on the shape of the wage offer distribution.

\subsection{Literature Review}

Empirical studies show that job-to-job transitions and wage bargaining are important features of labour markets. Nagypal (2008) documents that almost $50 \%$ of all job separations in the US are explained by job-to-job transitions. Hall and Krueger (2008) find that both wage posting and bilateral wage bargaining are equally important in the American labour market. Their survey data shows that the wage is determined by posting for 25 to $35 \%$ of workers, while it is determined by wage bargaining for around $34 \%$ of workers. Moreover, while wage posting is more common for lower educated workers and government jobs, wage bargaining is more common for more educated and professional workers.

Another empirical study is conducted by Jolivet et al. (2006). They use panel data for individuals covering 10 European countries and the USA. Both job-to-job and job-to-unemployment transition rates vary across countries. Whereas the fraction of job-to-job movers is relatively low in Italy (5.7\%), France (6.5\%) and Belgium (6.8\%), it is high in Ireland (16.5\%), Denmark $(20 \%)$ and the UK $(24.9 \%)$. Note that these numbers are reported over a three-year period. More than $50 \%$ of job-to-job transitions are associated with a wage increase in all countries even though there are also transitions with wage cuts.

In the past decades this empirical evidence was incorporated in the theoretical models of frictional labour markets. The seminal study providing a detailed characterization of wage ladders and job-to-job mobility is Burdett and Mortensen (1998) who developed a canonical on-the-job search model with homogenous workers and firms, where the wage is determined by a wage-posting game. Mortensen (2003) extended this model with Nash bargaining over wages. In particular, he compared two wage determinations, namely posting and bilateral bargaining where productivity heterogeneity over firms and endogenous recruiting effort is embodied. As a result, he concludes that bilateral bargaining wage determination can replicate Danish wage distribution and firm sizes, while wage posting hypothesis is not consistent with Danish data. One crucial assumption underlying the model is that the outside opportunity of bargaining workers is always unemployment irrespective of the worker's current wage. Pissarides (2000) and Flinn (2010) have extended the canonical on-the-job search model to account for firm heterogeneity but they keep the same restrictive assumption that the outside option of workers in the bargaining process is unemployment. Intuitively, this means that an unemployed individual and someone employed at a high wage will bargain the same new wage if matched with identical firms.

Another approach developed by Postel-Vinay and Robin (2002a, 2002b) proposes a new on-the-job search model in which heterogeneous employers are allowed to respond to workers outside offers. Hence there is a Bertrand competition among firms in order to hire a worker. 
When a worker receives an outside offer his/her current employer can make a counteroffer, so the worker will either enjoy a wage increase and stay or move to the new employer. This idea is further extended by Cahuc et al. (2006). They consider strategic wage bargaining between the incumbent and the poaching employer. The wage bargaining process is borrowed from Rubinstein (1982), infinite-horizon alternating-offers bargaining game. Another study by Gautier et al. (2010) investigates on-the-job search model with heterogeneous match qualities. Thus in their model workers are moving from less productive jobs to more productive jobs. They compare two wage setting regimes, one is wage posting where firms announce wages and commit to paying these wages, another one is Nash bargaining over wages. Here again the outside option of workers is assumed to be the state of unemployment.

Despite these numerous attempts to model on-the-job search, bilateral wage bargaining and heterogeneous firms in a unified framework, existing research is based on a number of restrictive assumptions. Some of the reviewed studies assume that the outside option of bargaining workers is always unemployment irrespective of their current wage position. Other studies consider counteroffers and Bertrand competition between the current and the new employer. Even though it is a realistic assumption for academic labour markets and top management positions in industrial companies it is rather rare in many other professions and occupations. Thus in this study we consider firms that negotiate over wages in the beginning of the employment relationship but don't match outside offers of other firms. Moreover, we explicitly take into account that workers employed at higher wages have a stronger bargaining position than unemployed workers. Note that implementing this approach in a setting with rational expectations of workers requires extreme assumptions concerning workers' knowledge and computing abilities, moreover, it renders the model analytically intractable. Thus we follow the approach summarized in Hommes (2013), Evans and Honkapohja (2001) and consider boundedly rational workers who use adaptive learning mechanisms and base their forecasts on time series data.

In general, the expectation formation plays an important role in economic models. The reason being that agents' current expectations affect the actual outcomes, and the actual outcomes affect their expectations in the next period (Hommes 2013). In the search and matching framework the focus of earlier studies was on expectation formation in the presence of asymmetric information and learning. For example, Jovanovic (1979) and Mortensen (1986) consider a setting where workers searching for jobs are not fully informed about the distribution of productivities. In this situation "the worker acts as a Bayesian forecaster by using observations to date to make predictions concerning the job's true but unknown characteristics. As new information arrives, the forecast is revised..." (Mortensen (1986), p. 877). In particular, both models assume that the productivity distribution is normal with unknown mean but known variance. So it is the average productivity that workers learn over time based on statistical data.

In the more recent search literature the focus is on group learning and peer pressure in the process of expectation formation. For example, Horvath (2015) develops a search model with wage bargaining to analyze the impact of social segregation on the wage gap between Black and White workers. The two worker groups have different social networks transmitting different social norms. The peer group of Black people transmits information that being unemployed is common as there are relatively many unemployed people in the social networks of Black workers. This gives rise to different expectations and different equilibrium outcomes of the two worker 
groups. In a similar vein Rotemberg (2017) shows that heterogeneous expectations of identical workers can lead to different wages. He considers a non-stationary wage offer distribution, such that wage offers are always low in the first time period, but can be high or low thereafter. There are two groups of workers: those with accurate information and group-learners who are not aware of the non-stationary of the wage offer distribution. Whereas the first group has a high reservation wage and a higher average wage in the equilibrium, the second group has low reservation wages and low equilibrium outcomes. The reason is that group learners observe low wages in their social network, which reduces their reservation wage and makes them accept low wage realizations in the first period. In sum both studies show that social norm or different beliefs among equally productive workers generated by segregated social networks may result in different wages. Earlier studies showing adverse effects of social networks on wages in a setting with bargaining and on-the-job search include Zaharieva $(2013,2015)$.

Further our study is related to the literature on learning mechanisms which can be divided into two strands. The first strand of literature shows that there are learning mechanisms such that model outcomes can asymptotically converge to the rational expectation outcomes. The second strand of literature emphasizes that convergence to the rational expectations outcomes is not guaranteed. Rather the model with learning may exhibit a complicated and different path than the rational expectation equilibrium.

The first group of studies includes Fourgeaud et al. (1986), Marcet and Sargent (1989), Bray and Savin (1986), Evans and Honkapohja (1994, 1995, 2001), Tuinstra and Wagener (2007), Marcet and Nicolini (2003), Böhm and Wenzelburger (1999) etc. An earlier study by Fourgeaud et al. (1986) provides the necessary and sufficient condition for the convergence and analytical proof for that in the model of Muth (1961). Basically the condition turns out that the coefficient of expectation is less than one. Marcet and Sargent (1989) consider general recursive linear models in which agents have limited access to the information and they are divided into differently informed two groups. Agents form expectations through recursive least square methods and update their parameters over time which is similar to our model. Under several technical assumptions they provide necessary and sufficient conditions for convergence to the rational equilibrium outcomes. Bray and Savin (1986) investigates the stability of the rational expectations equilibrium for linear version of Cobweb model with exogenous demand shock under the ordinary least squares (OLS) and Bayesian learning mechanisms. Firms form expectation about future price and decide their output level based on their expectations. Firms learn the parameters using these two linear regressions. They show that the estimated parameters converge to the rational expectation equilibria and are stable under the similar condition with Fourgeaud et al (1986). Tuinstra and Wagener (2007) and Marcet and Nicolini (2003) have used the OLS learning mechanism to forecast inflation in macroeconomic models. The second group of studies emphasizes the point that convergence to the rational expectations equilibrium depends on the learning mechanism and is not always guaranteed. For example, there can be new chaotic equilibria as in Bullard (1994) and Schönhofer (1999) such that the forecast errors of agents never vanish.

Hommes and Sorger (1998) introduce the notion of consistent expectation equilibria (CEE) belonging to the class of restricted perception equilibria. They show existence and stability of three types of equilibria in a Cobweb framework where the learning mechanism is sample 
autocorrelation (SAC) learning. CEE means that the sample average and the sample autocorrelations generated by the actual (unknown) stochastic process coincide with the corresponding statistics for the perceived linear process. This is similar in our model with recursive OLS learning since workers correctly perceive the correlation between productivities and wages without fully understanding the actual bargaining process. So there is consistency between the agents beliefs and the actual outcomes.

The paper proceeds as follows. In section 2 we explain the economic environment and derive the value functions for workers. In section 3 we introduce linear wage expectation formation and derive the value functions for firms. In the same section we analyze the theoretical outcome of Nash bargaining over wages and illustrate our results with a numerical example. In section 4 we introduce statistical learning and expectation updating in the agent-based simulation framework and summarize our results. Section 5 concludes the paper.

\section{The Model}

Time is continuous and workers are infinitely lived. The total population size is normalized to 1. Every worker can be employed $e$ or unemployed $u$, so that $e+u=1$. Unemployed workers receive the flow unemployment benefit $z$. Job-offers arrive at the Poisson arrival rate $\lambda$, which is the job-finding rate. Also employed workers receive job offers at rate $\lambda$. Upon the match workers learn the match-specific productivity $y$, which is a random variable with a cumulative distribution $Q(y)$ and density $q(y), z<y<\bar{y}$. This means that $Q(z)=0$ and $Q(\bar{y})=1$. Here $\bar{y}$ is the highest productivity draw which can also be infinity. If the productivity $y$ is higher than the current flow income of the worker, which is $z$ for the unemployed and $w$ for the employed, this worker and the employer bargain over the wage. The bargaining process will be described later in the paper. The worker is changing the job if the new bargained wage is higher than the current flow income $(z$ or $w)$. The option of waiting in this setting has zero value, since workers don't lose any opportunities by accepting jobs with a higher income. However, there can be inefficient transitions when workers move from more productive employers to less productive employers. This is due to the fact that there are no counter-offers of the current employer. So firms bargain over wages in the beginning of the employment relationship but don't renegotiate thereafter. We simplify the model by assuming that firms exit the market and get zero value if initial bargaining with the worker was not successful, thus firms always accept every worker as long as the bargained wage $w$ is below the productivity $y$. At rate $\delta$ any job can be destroyed and the worker becomes unemployed.

Workers are forward-looking but have limited foresight in the sense that they can not perfectly predict the outcomes of future bargaining. Let $x=\phi(y, w)$ be the expected future wage of the worker (increasing in both arguments) who is currently earning a wage $w$, was searching on-thejob and is matched with a new employer with productivity $y \geq w$. Assume that $\phi(w, w)=w$, so if the new employer has productivity $y=w$, the worker expects to get the same wage $w$ as with a current employer. $x=\phi(y, w)$ also means that we can write $y=\phi^{-1}(x, w)$. Unemployed workers expect a future wage $\phi(y, z)$. 


\subsection{Value functions}

Let $U$ be the present value of income in unemployment while $W(w)$ be the present value of employment at current wage $w$. The present value of unemployment $U$ is given by:

$$
r U=z+\lambda \int_{z}^{\bar{y}} \max [W(\phi(y, z))-U, 0] d Q(y)=z+\lambda \int_{y_{0}}^{\bar{y}}(W(\phi(y, z))-U) d Q(y)
$$

Unemployed workers receive the flow unemployment benefit $z$ and get job offers at rate $\lambda$. The integral reflects an expected gain from finding a job. Unemployed workers only accept jobs if the present value of the new job $W(\phi(y, z))$ is larger than the present value of unemployment $U$. Let $y_{0}$ be the reservation productivity of unemployed workers, defined as $W\left(\phi\left(y_{0}, z\right)\right)=U$. This means that unemployed workers will not accept any job with productivity below $y_{0}$. Further, assume that the value function $W(w)$ is increasing, so that $W^{\prime}(w)>0$. This gives rise to the second part of the above expression. We verify our assumption $W^{\prime}(w)>0$ later in the paper.

Next consider the present value of employment at the current wage $w$ :

$$
\begin{aligned}
r W(w) & =w+\lambda \int_{z}^{\bar{y}} \max [(W(\phi(y, w))-W(w)), 0] d Q(y)-\delta(W(w)-U) \\
& =w+\lambda \int_{w}^{\bar{y}}(W(\phi(y, w))-W(w)) d Q(y)-\delta(W(w)-U)
\end{aligned}
$$

This equation implies that employed workers are choosy and only accept jobs with a new present value $W(\phi(y, w))$ larger than the current present value $W(w)$. Since $\phi(w, w)=w$ we know that employed workers accept jobs with productivity $y$ above their current wage $w$, which gives rise to the second part of the above equation. At rate $\delta$ every worker may lose the job and becomes unemployed.

Evaluating $W(w)$ at wage $w=\phi\left(y_{0}, z\right)$ and using that $W\left(\phi\left(y_{0}, z\right)\right)=U$ we get:

$$
r U=\phi\left(y_{0}, z\right)+\lambda \int_{\phi\left(y_{0}, z\right)}^{\bar{y}}\left(W\left(\phi\left(y, \phi\left(y_{0}, z\right)\right)\right)-U\right) d Q(y)
$$

Comparing this equation with (1) we can see that $y_{0}=z$, so that unemployed workers always accept all jobs, because their productivity $y$ is larger than the reservation productivity $y_{0}=z$. This finding is an extension of the result by Burdett and Mortensen (1998) and is summarized in lemma 1:

Lemma 1 If workers are searching on-the-job and form expectations $x=\phi(y, w)$, where $w$ is the current wage and $y \sim Q(y), y \geq z$ is the productivity of the employer giving rise to the present values of (un)employment $U$ and $W(w), W^{\prime}(w)>0$, moreover, the job offer arrival rate $\lambda$ is the same in all states, $\phi(y, w)$ is increasing in both arguments and $\phi(w, w)=w$, then the reservation productivity $y_{0}$, defined as $W\left(\phi\left(y_{0}, z\right)\right)=U$, is equal to the unemployment benefit $z$.

Proof: Taking difference between equations (3) and (1) we get:

$$
z-\phi\left(y_{0}, z\right)=\lambda \int_{\phi\left(y_{0}, z\right)}^{\bar{y}}\left(W\left(\phi\left(y, \phi\left(y_{0}, z\right)\right)\right)-U\right) d Q(y)-\lambda \int_{y_{0}}^{\bar{y}}(W(\phi(y, z))-U) d Q(y)
$$

Suppose that $y_{0}>z$, so that $y_{0}=\phi\left(y_{0}, y_{0}\right)>\phi\left(y_{0}, z\right)>\phi(z, z)=z$. The left-hand side of the 
above equation is strictly negative. Now consider the right-hand side, which can be written as:

$$
\lambda \int_{\phi\left(y_{0}, z\right)}^{y_{0}}\left(W\left(\phi\left(y, \phi\left(y_{0}, z\right)\right)\right)-U\right) d Q(y)+\lambda \int_{y_{0}}^{\bar{y}}\left(W\left(\phi\left(y, \phi\left(y_{0}, z\right)\right)\right)-W(\phi(y, z))\right) d Q(y)
$$

Note that $W\left(\phi\left(\phi\left(y_{0}, z\right), \phi\left(y_{0}, z\right)\right)\right)=W\left(\phi\left(y_{0}, z\right)\right)=U$. Since $W(w)$ is increasing, we know that $W\left(\phi\left(y, \phi\left(y_{0}, z\right)\right)\right)>U$ for $y>\phi\left(y_{0}, z\right)$, so the first term of the above expression is strictly positive. Concerning the second term we know that $\phi\left(y, \phi\left(y_{0}, z\right)\right)>\phi(y, \phi(z, z))=\phi(y, z)$, which means that $W\left(\phi\left(y, \phi\left(y_{0}, z\right)\right)\right)-W(\phi(y, z))>0$ if $W(w)$ is increasing in $w$. This proves that the right-hand-side of the above expression is strictly positive. So $y_{0}>z$ can not be a solution. In a similar way, one can show that $y_{0}<z$ can not be a solution because the left-hand side is than strictly positive, while the right-hand side is strictly negative. So there exists a unique solution $y_{0}=z$ because $\phi(z, z)=z$ and $\phi(y, \phi(z, z))=\phi(y, z)$.

Lemma 1 shows that the standard result of Burdett and Mortensen (1998) that unemployed workers searching on-the-job don't reject any job offers with a wage above the unemployment benefit as long as the job-finding rate is the same in all states, extends to our setting. This is intuitive because unemployed workers don't lose any opportunities by following this strategy.

Further, rewrite the present value of employed workers $W(w)$ (using integration by parts and substituting $y=\phi^{-1}(x, w)$, see appendix) as:

$$
r W(w)=w+\lambda \int_{w}^{\phi(\bar{y}, w)}\left[1-Q\left(\phi^{-1}(x, w)\right)\right] W^{\prime}(x) d x-\delta(W(w)-U)
$$

where $\phi^{-1}(x, w)$ is the inverse function. Taking derivative of $W(w)$ with respect to $w$ and using that $Q(\bar{y})=1$ we obtain:

$$
(r+\delta+\lambda(1-Q(w))) W^{\prime}(w)=1-\lambda \int_{w}^{\phi(\bar{y}, w)} q\left(\phi^{-1}(x, w)\right) \frac{\partial \phi^{-1}(x, w)}{\partial w} W^{\prime}(x) d x
$$

In the next section we use this equation and continue the analysis with a linear expectation operator $\phi(y, w)$.

\section{$3 \quad$ Linear wage expectation operator}

Suppose workers use a linear wage expectation operator of the form $x=\phi(y, w)=\alpha y+(1-\alpha) w$ with $0<\alpha \leq 1$, so the expected future wage is a weighted average between $y$ and $w$. Even though workers don't have perfect foresight about the future, they expect that their future wage will be higher with a higher productivity of the new employer $y$. Moreover, workers receiving higher wages $w$ expect to get a higher wage from a new employer due to the stronger position in bargaining. This functional form satisfies our assumptions that $\phi(w, w)=w$. In the following we will consider the case when workers use past statistical data and estimate parameter $\alpha$ by means of the restricted OLS estimator. The inverse function is then $y=\phi^{-1}(x, w)=(x-(1-\alpha) w) / \alpha$ for $y \geq x \geq w$.

In addition, to simplify the problem we consider an exponential distribution of productivities $Q(y)=1-e^{-\gamma(y-z)}$ and $q(y)=\gamma e^{-\gamma(y-z)}$. This is a shifted exponential distribution with the lowest productivity equal to $z$ and the average productivity equal to $1 / \gamma$. This distribution is 
inline with empirical findings about the decreasing density of the productivity distribution. For example, Gaffeo et al (2003) use accounting data on sales, total capital and total loan capital of firms and find decreasing densities of firm types with long right tails in all three cases. In the end of the paper we perform a robustness check by varying parameter $\gamma$ and show numerically that our results do not depend on the shape of the productivity distribution. Given the above assumptions we get:

$$
r W(w)=w+\lambda \int_{w}^{\infty} e^{-\gamma \frac{(x-(1-\alpha) w-\alpha z)}{\alpha}} W^{\prime}(x) d x-\delta(W(w)-U)
$$

Differentiating this equation with respect to $w$ we get:

$$
\begin{aligned}
\left(r+\delta+\lambda e^{-\gamma(w-z)}\right) W^{\prime}(w) & =1+\frac{\lambda(1-\alpha)}{\alpha} \int_{w}^{\infty} \gamma e^{-\gamma \frac{(x-(1-\alpha) w-\alpha z)}{\alpha}} W^{\prime}(x) d x \\
& =1+\frac{\gamma(1-\alpha)}{\alpha}(r W(w)-w+\delta(W(w)-U))
\end{aligned}
$$

Let $k \equiv r+\delta$ to simplify the notation. Next consider a benchmark case $\alpha=1$, which corresponds to the situation when workers expect to receive wages equal to the marginal productivity $y$. Inserting $\alpha=1$ and $W^{\prime}(w)=1 /\left(k+\lambda e^{-\gamma(w-z)}\right)$ into equation (4) we find the following value function:

$$
r W(w)=z+\frac{1}{\gamma}\left[\ln \left(k e^{\gamma(w-z)}+\lambda\right)-\ln k\right]-\delta(W(w)-U)
$$

Further, we estimate this function at $w=z$ and use the definition of the reservation wage $W(z)=$ $U$ to find the present value of unemployment $U$. This yields $U=z / r+(1 / \gamma r)[\ln (k+\lambda)-\ln k]$. This expression shows that unemployed workers gain higher present value when the unemployment benefit $z$ is higher, firms are more productive (lower $\gamma$ ) and finding jobs is easier (higher $\lambda$ ). Finally, rearranging the terms we find the present value of employment $W(w)$ (appendix II):

$$
W(w)=\frac{z}{r}+\frac{\ln \left(k e^{\gamma(w-z)}+\lambda\right)-\ln (k+\lambda)}{\gamma k}+\frac{\ln (k+\lambda)-\ln k}{\gamma r}
$$

In the benchmark case $\alpha=1$ function $W(w)$ is strictly increasing and convex in $w$ :

$$
W^{\prime}(w)=\frac{e^{\gamma w}}{\left(k e^{\gamma w}+\lambda\right)}>0 \quad W^{\prime \prime}(w)=\frac{\gamma \lambda e^{\gamma w}}{\left(k e^{\gamma w}+\lambda\right)^{2}}>0
$$

Intuitively $\alpha=1$ means that workers always expect to get a wage $w$ equal to their full productivity $y$. This expectation is rational, for example, when the bargaining power of workers $\beta$ is equal to 1 . In all other cases when $\beta<1$ and $\alpha<1$, we consider boundedly rational workers. Thus we proceed with a more general case when $0<\alpha<1$. Equation (5) yields the following first order linear differential equation for $W(w)$ :

$$
W^{\prime}(w)=\frac{\alpha-\gamma(1-\alpha)(w+\delta U)}{\alpha\left(k+\lambda e^{-\gamma(w-z)}\right)}+\frac{\gamma(1-\alpha) k}{\alpha\left(k+\lambda e^{-\gamma(w-z)}\right)} W(w)
$$

The general solution of this equation and its properties are summarized in proposition 1: 
Proposition 1: The general solution of the first order linear differential equation (6) is:

$$
\tilde{W}(w)=\left(k e^{\gamma(w-z)}+\lambda\right)^{\frac{1-\alpha}{\alpha}}\left(\int_{z}^{w} \frac{(\alpha-\gamma(1-\alpha)(x+\delta U))}{\alpha\left(k+\lambda e^{-\gamma(x-z)}\right)}\left(k e^{\gamma(x-z)}+\lambda\right)^{-\frac{(1-\alpha)}{\alpha}} d x+C\right)
$$

Moreover, the present value of unemployment is given by $U=(k+\lambda)^{\frac{1-\alpha}{\alpha}} C$, where the integration constant $C$ can be found as:

$$
\begin{aligned}
r k^{\frac{1-\alpha}{\alpha}} C & =z+\lambda \int_{z}^{\infty} e^{-\gamma \frac{(w-z)}{\alpha}} A^{\prime}(w) d w \quad \text { where } \\
A(w) & \equiv\left(k e^{\gamma(w-z)}+\lambda\right)^{\frac{1-\alpha}{\alpha}} \int_{z}^{w} \frac{(\alpha-\gamma(1-\alpha) x)\left(k e^{\gamma(x-z)}+\lambda\right)^{-\frac{1-\alpha}{\alpha}}}{\alpha\left(k+\lambda e^{-\gamma(x-z)}\right)} d x
\end{aligned}
$$

\section{Proof: Appendix I}

Proposition 1 yields a general solution of equation (6). However, for it to be a valid value function we have to verify that $\tilde{W}(w)$ is an increasing function of $w$. In the following proposition we present explicit analytical solutions in the three special cases with $\alpha=1 / 2, \alpha=1 / 3$ and $\alpha=1 / 4$ and show that in these cases $\tilde{W}(w)$ is a strictly increasing function of $w$, therefore, it is a valid value function.

Proposition 2: Consider a special case when the unemployment benefit $z$ is zero.

a) For $\alpha=1 / 2$, the value functions of employed and unemployed workers $W(w)$ and $U$ are:

$$
\begin{aligned}
& k W(w)=w+\delta U+\frac{\left(k e^{\gamma w}+\lambda\right)\left[\ln \left(k+\lambda e^{-\gamma w}\right)-\ln k\right]}{\gamma \lambda}-\frac{1}{\gamma} \\
& r U=\frac{(k+\lambda)}{\gamma}\left[\frac{\ln (k+\lambda)-\ln k}{\lambda}-\frac{1}{k+\lambda}\right], \quad W^{\prime}(w)>0, W^{\prime \prime}(w)>0
\end{aligned}
$$

b) For $\alpha=1 / 3$, the value functions of employed and unemployed workers $W(w)$ and $U$ are:

$$
\begin{aligned}
& k W(w)=w+\delta U+\frac{\left(k e^{\gamma w}+\lambda\right)^{2}\left[\ln \left(k+\lambda e^{-\gamma w}\right)-\ln k\right]}{\gamma \lambda^{2}}-\frac{\left(k e^{\gamma w}+\lambda\right)}{\gamma \lambda}-\frac{1}{2 \gamma} \\
& r U=\frac{(k+\lambda)^{2}}{\gamma \lambda}\left[\frac{\ln (k+\lambda)-\ln k}{\lambda}-\frac{1}{k+\lambda}-\frac{\lambda}{2(k+\lambda)^{2}}\right], \quad W^{\prime}(w)>0, W^{\prime \prime}(w)>0
\end{aligned}
$$

c) For $\alpha=1 / 4$, the value functions of employed and unemployed workers $W(w)$ and $U$ are:

$$
\begin{aligned}
& k W(w)=w+\delta U+\frac{\left(k e^{\gamma w}+\lambda\right)^{3}\left[\ln \left(k+\lambda e^{-\gamma w}\right)-\ln (k)\right]}{\gamma \lambda^{3}}-\frac{\left(k e^{\gamma w}+\lambda\right)^{2}}{\gamma \lambda^{2}}-\frac{k e^{\gamma w}+\lambda}{2 \gamma \lambda}-\frac{1}{3 \gamma} \\
& r U=\frac{(k+\lambda)^{3}}{\gamma \lambda^{2}}\left[\frac{[\ln (k+\lambda)-\ln (k)]}{\lambda}-\frac{1}{k+\lambda}-\frac{\lambda}{2(k+\lambda)^{2}}-\frac{\lambda^{2}}{3(k+\lambda)^{3}}\right], \quad W^{\prime}(w)>0, W^{\prime \prime}(w)>0
\end{aligned}
$$

\section{Proof: Appendix II.}

Recall that $W(w)$ is increasing and convex in the benchmark case $\alpha=1$. Proposition 2 shows that even for lower values of $\alpha$ equal to $1 / 2,1 / 3$ and $1 / 4$ this property holds and there exists a valid value function $W(w)$. Figure 1 plots $W(w)$ and shows that the value function is increasing and convex in $w$ also for the intermediate values of $\alpha$. Overall, we can see that more optimistic beliefs of workers with higher values of $\alpha$ give rise to higher value functions. The upper curve corresponds to the case $\alpha=1$ when workers expect to receive their full output: 
$\phi(y, w)=y$. In the opposite case when $\alpha \rightarrow 0$, the present values of employed and unemployed workers become $\lim _{\alpha \rightarrow 0} U=0$ and $\lim _{\alpha \rightarrow 0} W(w)=w / k$ since the unemployment benefit $z$ is normalized to zero and workers don't expect anything better in the future than their current flow income $\phi(y, w)=w$. So the value function $W(w)$ becomes linear in $w$ when $\alpha \rightarrow 0$.

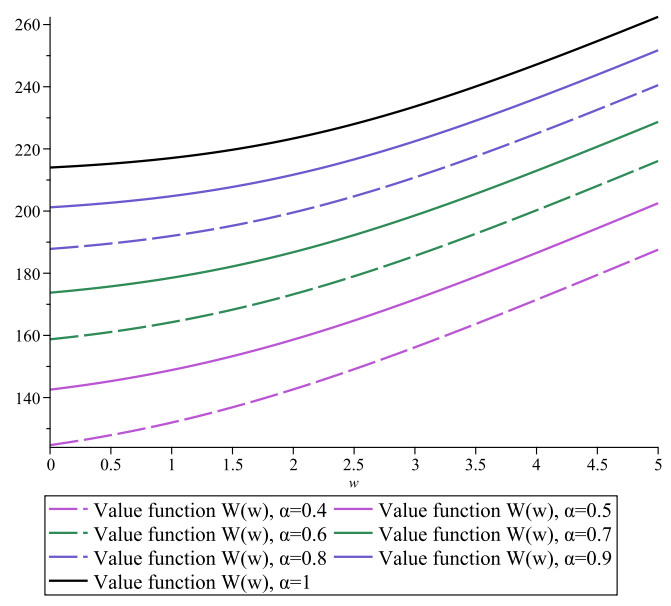

\begin{tabular}{ll}
\hline \hline Description & Values \\
\hline \hline Job destruction rate & $\delta=0.05$ \\
Discount rate & $r=0.01$ \\
Job offer rate & $\lambda=0.45$ \\
Exponential intensity & $\gamma=1$ \\
Unemployment benefit & $z=0$ \\
\hline
\end{tabular}

Figure 1: Left panel: Value functions of workers for different parameters $\alpha$. Right panel: Benchmark parameter setting

To illustrate the value function we use parameters from the right table of figure 1 . In particular, we set one period of time to be one quarter and the annual discount rate equal to $4 \%$. This implies a quarterly value of $r=0.01$. The job destruction rate is set at $\delta=0.05$ and the job offer rate is $\lambda=0.45$. This leads to the steady state unemployment rate $u=\delta /(\delta+\lambda)=0.1$, that is $10 \%$. The intensity parameter of the exponential distribution is set at $\gamma=1$, so the average productivity type is equal to 1 . At the same time $63 \%$ of firms have productivity below 1. Note that the average productivity in the steady state will be higher than 1 since jobs with more (less) productive employers are more (less) stable. These parameters will be used throughout the study. Next we move to the analysis of firms' profits and bargaining.

\subsection{Profits of firms}

In this section we take the perspective of firms and consider their profits. Let $J(y, w)$ be the present value of a filled job for the firm with productivity level $y$ which pays the employed worker wage $w$. The present value of a filled job $J(y, w)$ is given by:

$$
r J(y, w)=(y-w)-\delta J(y, w)-\lambda(1-Q(w)) J(y, w)
$$

Firms receive the flow profit $(y-w)$ and may lose their workers if the job is destroyed at rate $\delta$ or when workers quit with probability $\lambda(1-Q(w))$. Note here that workers quit whenever they are matched with a new employer whose productivity is higher than the current wage of the worker $w$. In some cases these quits can be socially inefficient since workers change from more productive employers to less productive ones. This happens, for example, if $w<y^{\prime \prime}<y$, where $y^{\prime \prime}$ is the new employer's productivity. In the opposite case when $w<y<y^{\prime}$ workers move to more productive employers with productivity $y^{\prime}$ and the transition is socially efficient. This is illustrated on figure 2. The probability that $w<y^{\prime}$ is given by $(1-Q(w))$. 


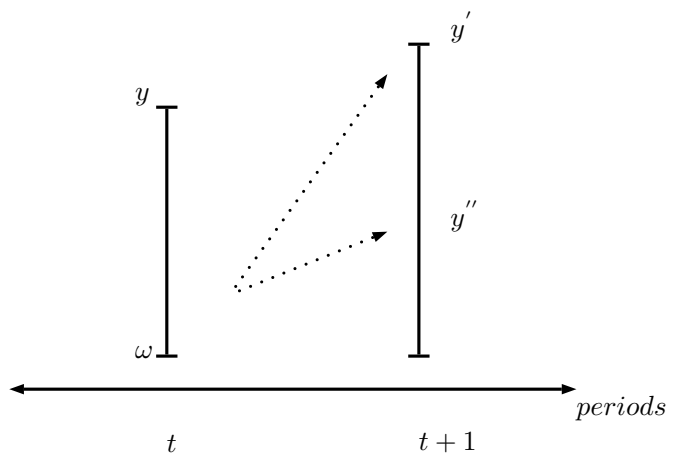

Figure 2: Workers' transitions

The present value of a filled job can be rewritten as:

$$
J(y, w)=\frac{y-w}{r+\delta+\lambda(1-Q(w))}
$$

We can observe that a higher wage $w$ has both a negative and a positive effect on firm's profit. On the one hand, the flow profit per unit of time in the numerator is lower with a higher wage. But on the other hand, the quitting probability in the denominator is also lower with a higher wage. This means that firms receive the profit over a longer period of time. Therefore, the profit function can be hump-shaped. Next, consider the first order derivative of $J(y, w)$ with respect to $w$ and use that $k=r+\delta$ and $1-Q(w)=e^{-\gamma(w-z)}$ :

$$
J^{\prime}(y, w)=\frac{(-1)\left(k+\lambda e^{-\gamma(w-z)}\right)+(y-w) \lambda \gamma e^{-\gamma(w-z)}}{\left(k+\lambda e^{-\gamma(w-z)}\right)^{2}}
$$

In order to find a wage that maximizes the present value of profits we set $J^{\prime}(y, w)=0$, so the first order condition becomes:

$$
k e^{\gamma(w-z)}+\lambda=(y-w) \lambda \gamma
$$

We can see that the left-hand side of this expression is strictly increasing in $w$ starting at the lowest value $k+\lambda$ when $w=z$. In contrast, the right-hand side is a linear decreasing function starting at the highest value $(y-z) \lambda \gamma$. So there exists a unique solution of this equation whenever $k+\lambda<(y-z) \lambda \gamma$. Let this solution be denoted by $w^{*}(y)$. Intuitively, this means that the profit maximization problem has the corner solution whenever $k+\lambda>(y-z) \lambda \gamma$. Otherwise there exists a unique value $w^{*}(y)$ which is maximizing the firm profit $J(w, y)$. This results are summarized in lemma 2 :

Lemma 2: Let $y^{*}$ denote the productivity threshold which is given by $y^{*}=\frac{k+\lambda}{\lambda \gamma}+z$. Firms with low productivity $y<y^{*}$ have a strictly decreasing profit function $\forall w>z$. For more productive firms with $y>y^{*}$ there exists a unique profit maximizing wage $w^{*}(y)>z$ given by equation (7):

$$
\text { If } y>y^{*} \Rightarrow \begin{cases}J^{\prime}(y, w)>0, & \text { for } w<w^{*}(y) \\ J^{\prime}(y, w)<0, & \text { for } w>w^{*}(y)\end{cases}
$$


The profit function $J(y, w)$ is concave, that is $J_{w}^{\prime \prime}(y, w)<0$, for $w^{*}(y)<w<y$.

\section{Proof: Appendix III.}

Intuitively lemma 2 means the following. Very unproductive firms with $y<y^{*}$ realize that they can not compete with other firms for workers. If they had a full bargaining power over the wage, they would choose the lowest wage $w=z$. This is different for more productive firms with $y>y^{*}$. Conditional on having full bargaining power they would set a wage strictly above $z$ to reduce the probability of worker quitting. However, a situation when firms possess full bargaining power is not realistic, so we continue with the analysis of Nash bargaining with an interior bargaining weight in the next subsection.

\subsection{Wage determination}

Wages are determined by individual bargaining between the worker and the firm. Specifically, we use the generalized Nash bargaining concept. Let $w_{0}$ be the current wage of the worker and $0<\beta<1$ be the workers' bargaining power. We assume that the new employer is informed about the current wage $w_{0}$. If there is disagreement, the worker remains with the previous employer and gets a present value of $W\left(w_{0}\right)$, while the firm exists the market with nothing. If negotiation succeeds, then the joint productivity of the worker and the firm becomes $y$, the worker receives the wage $w$ with a present value $W(w)$ and firm's expected profit becomes $J(y, w)$. Thus, the Nash objective function can be written as:

$$
w=\arg \max \left(W(w)-W\left(w_{0}\right)\right)^{\beta} J(y, w)^{1-\beta}
$$

The bargaining solution $w$, maximizing the Nash objective function must satisfy the firstorder condition:

$$
\beta J(y, w) W^{\prime}(w)=-(1-\beta)\left(W(w)-W\left(w_{0}\right)\right) J_{w}^{\prime}(y, w)
$$

If the bargaining power of workers is close to 1 , this equation implies that workers set their wage equal to the productivity $y$. In the opposite extreme case, when $\beta=0$, this equation implies that $J_{w}^{\prime}(y, w)=0$. We already know from the previous section that firms with productivity above $y^{*}$ will want to set a profit maximizing wage $w^{*}(y)$ as long as this wage is above the current wage of the worker $w_{0}$. This means $\max \left[w_{0}, w^{*}(y)\right]<w<y$. In general note that any solution of the above equation implies that $J_{w}^{\prime}(y, w)<0$, so that both sides of the equation are positive. This is intuitive, because the outcome of negotiation should lie on the Pareto frontier where firms resist further wage increases. A wage such that $J_{w}^{\prime}(y, w)>0$ can not be an outcome of the bargaining problem since in this case both workers and firms will gain by negotiating a wage increase.

Let $w\left(y, w_{0}\right)$ denote solution of equation (9), that is the outcome of the bargaining process. Even though in general we can not prove that this solution is unique for all parameter values, it is possible for parameters described in proposition 2 :

Lemma 3: Consider the following special cases $\alpha=1 / 4, \alpha=1 / 3, \alpha=1 / 2$ and $\alpha=1$ and let the unemployment benefit $z$ be normalized to zero. Then the Pareto frontier of the generalized Nash bargaining problem (8) is decreasing and concave. Given that the Nash objective function (8) implies a decreasing convex relation between $W$ and $J$, the generalized Nash bargaining 
solution $w\left(y, w_{0}\right)$ is unique.

Proof: Lemma 2 shows that firms with low productivity $\left(y<y^{*}\right)$ have a decreasing present value of profits in the whole range $\left[w_{0} . . y\right]$. For more productive firms $\left(y>y^{*}\right)$ consider first the case $w_{0}<w^{*}(y)$. It is clear that the range $\left[w_{0} . . w^{*}(y)\right]$ is not Pareto optimal as both workers and firms would agree on a higher wage. However, for $w>w^{*}(y)$ we already know that the profit function is decreasing. In the second case when $w_{0}>w^{*}(y)$ the profit function is again decreasing in the whole range $\left[w_{0} . . y\right]$. So the feasible set of wages that satisfy Pareto optimality is given by $\left[\max \left(w_{0}, w^{*}(y)\right) . . y\right]$. The profit function $J(w, y)$ is decreasing in $w$ in this range, while the workers' value function $W(w)$ is increasing and convex.

Let $w(J, y)$ be the unique inverse function of $J(w, y)$ in the range $w \in\left[\max \left(w_{0}, w^{*}(y)\right) . . y\right]$. The Pareto frontier is then given by $W(w(J, y))$. Differentiate $W(w(J, y))$ with respect to $J$ :

$$
\begin{aligned}
\frac{\partial W(w(J, y))}{\partial J} & =\frac{\partial W}{\partial w(J, y)} \cdot \frac{\partial w(J, y)}{\partial J}=\frac{\partial W}{\partial w(J, y)} \cdot \frac{1}{\partial J(w, y) / \partial w}<0 \\
\frac{\partial W^{2}(w(J, y))}{\partial J^{2}} & =\frac{\partial^{2} W}{\partial w(J, y)^{2}} \cdot \frac{\partial w(J, y)}{\partial J}+\frac{\partial W}{\partial w(J, y)} \cdot \frac{\partial^{2} w(J, y)}{\partial J^{2}} \\
& =\frac{\partial^{2} W}{\partial w(J, y)^{2}} \cdot \frac{1}{\partial J(w, y) / \partial w}-\frac{\partial W}{\partial w(J, y)} \cdot \frac{\partial^{2} J}{\partial w(J, y)^{2}}\left(\frac{1}{\partial J(w, y) / \partial w}\right)^{3}<0
\end{aligned}
$$

where in the last line we used the property of the inverse second order derivative and the fact that $\partial^{2} J / \partial w^{2}<0$ for $w>w^{*}(y)$ (lemma 2). This proves that the Pareto frontier is decreasing and concave. Further let us fix the Nash objective function to some constant level $K$. It is straightforward to show that this function $W=W\left(w_{0}\right)+K J^{-\frac{(1-\beta)}{\beta}}$ describes a negative convex relationship between $W$ and $J$. This completes the proof.

This lemma shows that the Pareto frontier corresponding to wages $w \in\left[\max \left(w_{0}, w^{*}(y)\right) . . y\right]$ is a decreasing and concave function in the space $[J, W]$. However, the Nash objective function $\left(W-W\left(w_{0}\right)\right)^{\beta} J^{1-\beta}$ is decreasing and convex. So the tangency point which gives the Nash bargaining solution $w\left(w_{0}, y\right)$ is unique. Note that the same is true in the reverse space $[W, J]$. In the section with numerical results we show that this property holds more generally also for other values of $\alpha$.

Consider a special case when $\alpha=1$, so the modified first order condition can be written as:

$$
\beta(y-w)=-(1-\beta) \frac{\left[\ln \left(k e^{\gamma w}+\lambda\right)-\ln \left(k e^{\gamma w_{0}}+\lambda\right)\right]}{k \gamma}\left[(y-w) \lambda \gamma e^{-\gamma w}-\left(k+\lambda e^{-\gamma w}\right)\right]
$$

Even though we can not characterize a general function $w\left(y, w_{0}\right)$ for all parameter values, lemma 4 summarizes our results for the special case $\alpha=1$.

Lemma 4: Consider a special case when $\alpha=1$ and $z=0$. Then the unique solution of the bargaining problem (8) is implicitly given by equation (10), moreover, the bargained wage $w\left(y, w_{0}\right)$ is strictly increasing in both arguments:

$$
\frac{\partial w\left(y, w_{0}\right)}{\partial y}>0 \quad \text { and } \quad \frac{\partial w\left(y, w_{0}\right)}{\partial w_{0}}>0
$$

\section{Proof: Appendix III.}

This lemma shows that in the special case $\alpha=1$, bargained wages are increasing in the productivity of the firm $y$ and in the current wage of the worker $w_{0}$. This means that two 
workers may bargain different wages with the same employer if their pre-bargaining situation was different. Note that we assume no possibility of waiting for firms. That is the firm exits the market if the negotiation with the applicant was not successful. This is a simplifying assumption of the model. In the opposite case, if firms could wait for another applicant, it is possible that they would reject applicants with very strong bargaining positions implying very low profits for the firm. Next we address a question whether the wage function has the same properties for a wider range of $\alpha$-s. Given that we can not prove it analytically, we proceed with the numerical results in the next subsection.

\subsection{Comparative statics}

In this section we analyze numerically how the bargained wage depends on the characteristics of workers and firms. We start by plotting the present value of profits $J(y, w)$ for different values of $y$ and $w$ on the left panel of figure 3. This figure illustrates that the profit maximization problem has internal solution when the productivity level $y$ is higher than the productivity threshold $y^{*}$ while there is a corner solution otherwise. Our choice of parameters is summarized in the table on figure 1 . These parameters imply that $y^{*}=1.13$, so that firms with productivity below 1.13 have strictly decreasing profit functions. The highest curve corresponds to the productivity level $y=3.5$. Only $3 \%$ of matches in our model have productivity above this level. Thus this figure shows the profit functions for the majority of firms.
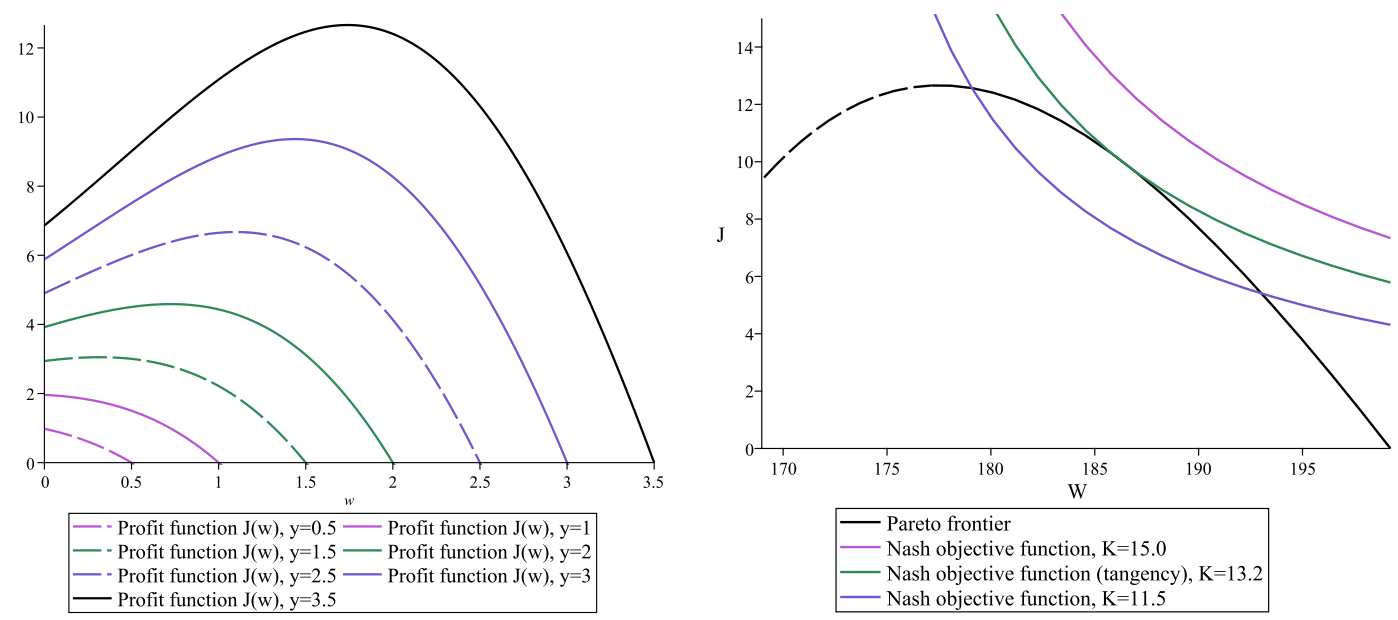

Figure 3: Left panel: Firms' value functions for different productivities. Right panel: Nash objective function for different values of $K, w_{0}=0.5, y=3.5, \alpha=0.65, \beta=0.5$

On the right panel of figure 3 we illustrate the Pareto frontier (black solid curve) given by $J(y, w(W))$ and several Nash objective functions given by $\left(W-W\left(w_{0}\right)\right)^{\beta} J^{1-\beta}=K$. We can see that the set of feasible combinations of $J$ and $W$ is convex, but the dashed part of the frontier is not Pareto optimal. Inline with lemma 3 the Pareto frontier is concave, while the Nash objective function is convex, which yields a unique tangency point. On the figure this point corresponds to the optimal wage $w=2.50$ generating an allocation $[W=185.6, J=10.32$,$] on the figure.$ Note that the firm has productivity $y=3.5$ and the current wage of the worker is $w_{0}=0.5$. The bargaining power $\beta=0.5$, while the expectation coefficient $\alpha=0.65$. In the extreme case when $\beta=1$, the Nash objective function is represented by the vertical line, so the wage is equal to the 
productivity $w=y=3.5$. In this case workers get their maximal value $W=199.2$. In contrast, when $\beta=0$, the Nash objective function becomes horizontal, so firms set a wage $w=1.74$, which corresponds to the allocation $[W=177.13, J=12.66$, $]$ with the highest possible present value of profits for firms. Overall, this figure shows that the Nash solution is unique in our setting even though we can only prove it analytically for several selected values of $\alpha$ (see lemma 3).

On figure 4 we fix the productivity of firms $y=3.5$ and analyze the implications of different worker types and their expectations. In particular, on the left panel we increase the current wage of the applicant $w_{0}$ between 0.5 and 2 . We can see again that in all cases there exists a unique wage maximizing the Nash bargaining product and this wage is increasing in $w_{0}$. Note that firms with productivity $y=3.5$ will always agree to pay at least a wage $w^{*}(3.5)=1.74$, which is maximizing their individual profit. This implies that all bargained wages are compressed in the range $[1.74 \ldots 3.5]$.
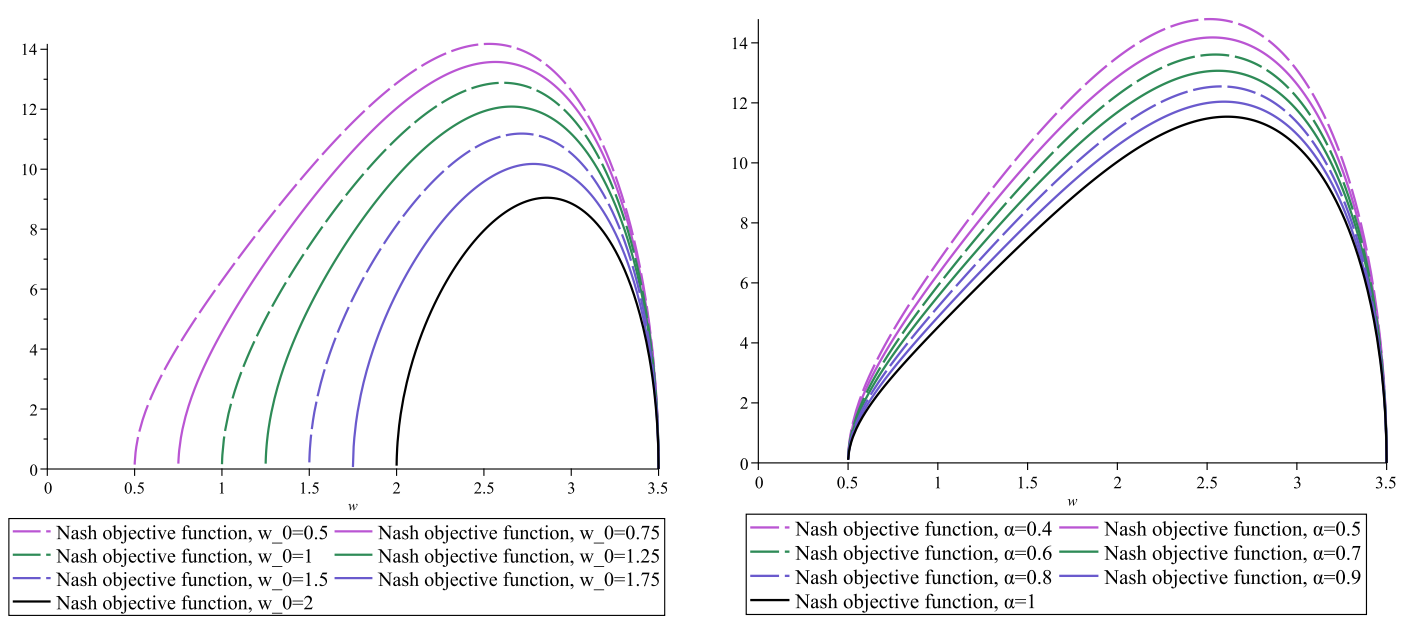

Figure 4: Nash objective function for different values of $w_{0}$ and $\alpha, \beta=0.5, y=3.5$

On the right panel of figure 4 we present comparative statics with respect to $\alpha$ varying it between 0.4 and 1 . Workers are pessimistic for low values of alpha but they are optimistic in the opposite case. For instance, when $\alpha=0.4$ the worker's expected wage is equal to $0.4 \cdot 3.5+(1-0.4) \cdot 0.5=1.7$ and the bargained wage is 2.51 . Clearly, the worker underestimates his/her actual wage. In contrast, for higher $\alpha$, when $\alpha=1$ the worker's expected wage is 3.5 and the bargained wage is 2.61 , the worker overestimates the actual wage. Overall, we can see that more optimistic workers with higher $\alpha$-s bargain higher wages.

Finally on figure 5 we analyze the impact of productivities on wage. On the left panel we illustrate the Nash objective function for different productivity levels $y$ ranging between 2 and 3.5. We also use a bargaining power parameter $\beta=0.5$, and the expectation coefficient $\alpha=0.5$. The current wage of the worker is $w_{0}=0.5$ for the purpose of this illustration. We can see that for all considered productivities there exists a unique wage which is maximizing the Nash objective function. Moreover, the bargained wages are increasing with $y$. The right panel plots wages against productivities $y$ and starting wages $w_{0}$. We already know that bargained wages are increasing in both arguments. This figure reveals additionally, that the wage $w\left(y, w_{0}\right)$ is a convex function of both arguments. The lowest dashed curve corresponds to the situation when unemployed $(z=0)$ workers bargain over wages, while upper curves show wages of employed 


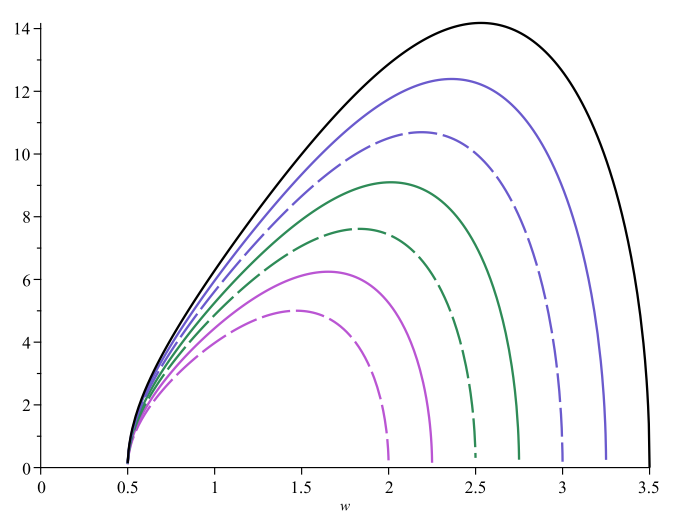

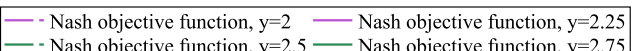

- Nash objective function, $y=2.5$ - Nash objective function, $y=2.75$ Nash objective function, $\mathrm{y}=3$.

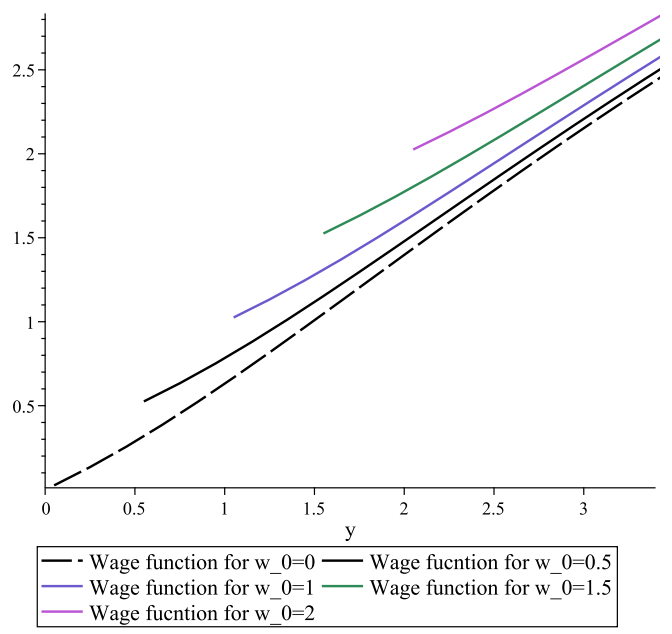

Figure 5: Left panel: Nash objective function for different values of $y, w_{0}=0.5, \beta=0.5$, $\alpha=0.5$. Right panel: Wage as a function of $y$ and $w_{0}, \beta=0.5, \alpha=0.65$

workers changing employers. Moreover, this figure shows that negotiated wages are more sensitive to the bargaining positions of workers (reflected in $w_{0}$ ) when workers bargain with less productive employers. So the variation in wages due to $w_{0}$ is large (small) when workers are matched with less (more) productive employers.

\section{Simulation results}

\subsection{Statistical learning mechanism}

Agent-based simulation is a common tool for the analysis of dynamics in complex systems. In particular, agent-based models are based on the bottom up approach and allow to analyze the interaction of heterogeneous agents according to some behavioral rules relaxing such assumptions as rational expectations, perfect information and representative agents. Interestingly, one can observe the emergence of macroeconomic outcomes through the microeconomic interaction of many agents, moreover, agent-based models are able to reproduce stylized empirical facts in labour economics and macroeconomics (Dosi et al. 2006). For instance, the stylized facts that are often considered in labour economics include the matching function, the wage density and the firm size distribution which have been shown to be highly skewed.

According to Neugart and Richiardi (2018) labour market agent-based models can be divided into two categories: partial models and labour market models which are embedded in the agentbased macroeconomic framework in various settings. The main results and features of these models are discussed extensively in Neugart and Richiardi (2018) for the first category and in Dawid and Delli Gatti (2018), in Delli Gatti et al (2018) for the second category respectively. Many studies have been carried out recently in various scopes using partial models such as Gemkow and Neugart (2011), Lewkovicz et al. (2009), Neugart (2004), Richiardi (2004, 2006) and Ballot (2002). For example, Richiardi (2006) develops an on-the-job search model with entrepreneurial decisions, endogenous wage determination and endogenous matching between works and firms. The model relies on the assumption that wages are determined by a firm specific constant fraction of the worker's productivity. It is shown that the model is able to 
reproduce several important stylized facts such as the Beverage curve, the Okun curve, and wage, income and firm size distributions. Our model is also conducted in the partial equilibrium framework and the main purpose of the simulation is to collect data on workers' transitions, their wages and productivities. These data is used by workers to update their wage expectations.

In the previous section we have characterized the bargained wage function $w\left(y, w_{0}\right)$ assuming that workers expect a wage $\phi\left(y, w_{0}\right)$. In the equilibrium with rational expectations and perfect foresight we would require that $w\left(y, w_{0}\right)=\phi\left(y, w_{0}\right)$ for all productivity realizations $y$ and for all previous wages $w_{0}$. This means that workers know precisely the outcome of the bargaining process with every possible employer. However, this condition requires extreme assumptions concerning workers' knowledge and computing abilities, moreover, it renders the model analytically intractable. For this reason we consider boundedly rational agents with limited foresight as a more realistic description of human behavior. Following the literature on bounded rationality we assume that workers use adaptive learning mechanisms and base their forecasts on time series data. Thus workers in our model behave as economic statisticians and update their beliefs over time as new data becomes available.

In the previous sections we already assumed that workers use a linear expectation operator $\phi\left(y, w_{0}\right)=\alpha y+(1-\alpha) w_{0}$ in order to form their forecasts. In this section we continue the analysis by acknowledging that the best linear unbiased estimator of $\alpha$ can be obtained from the OLS regression. Statistical data is generated by means of the agent-based simulation. Let $w_{i t}$ denote the current wage of worker $i$ in time period $t$, with $y_{i t}$ being the corresponding productivity and $w_{i t-1}$ being the previous wage of the worker. We regress net wage changes $w_{i t}-w_{i t-1}$ on net productivity changes $y_{i t}-w_{i t-1}$ restricting the sample to workers who found a new job or changed the employer voluntarily, so that $w_{i t}-w_{i t-1}>0$ :

$$
w_{i t}-w_{i t-1}=\alpha\left(y_{i t}-w_{i t-1}\right)+\varepsilon_{i t}
$$

Note that we restrict the intercept of the regression to be zero for economic reasons since we know that $w_{i t}-w_{i t-1}=0$ if $y_{i t}-w_{i t-1}=0$. If this restriction is correct than the restricted OLS estimator is unbiased. Furthermore, we consider a setting where all workers have access to aggregate statistical information announced by the statistical office/agency. This statistical office collects empirical data on wages $w_{i t}$ and productivities $y_{i t}$ of all workers in the economy. The expectation coefficient $\alpha$ is updated in every period in time, so we use notation $\alpha_{t}$, and released to workers. It is convenient to think that there exists a statistical authority in the economy which is collecting administrative data and informing workers about aggregate statistical variables. But it is not relevant for our analysis whether empirical data is used directly by every worker or collected and transmitted by the statistical authority. What is important is that all workers in the economy have access to the same statistical information, which leads to the homogeneity of workers' beliefs. The statistical office minimizes the sum of squared errors over all workers $i=1 . . n$ and all periods of time $\tau=0 . . t-1$ using a recursive OLS mechanism:

$$
\min _{\alpha_{t}} \sum_{\tau=1}^{t-1} \sum_{i=1}^{n} \epsilon_{i \tau}^{2} \quad \text { where } \quad \epsilon_{i \tau}=w_{i \tau}-w_{i \tau-1}-\alpha_{t}\left(y_{i \tau}-w_{i \tau-1}\right)
$$

Note again that the sample is restricted to workers who found a new job or changed the employer 
voluntarily, so that $w_{i \tau}-w_{i \tau-1}>0$. The estimated accumulated coefficient $\hat{\alpha}_{t}$ can be obtained as follows:

$$
\hat{\alpha}_{t}=\frac{\sum_{\tau=1}^{t-1} \sum_{i=1}^{n}\left(w_{i \tau}-w_{i \tau-1}\right)\left(y_{i \tau}-w_{i \tau-1}\right)}{\sum_{\tau=1}^{t-1} \sum_{i=1}^{n}\left(y_{i \tau}-w_{i \tau-1}\right)^{2}}
$$

One can see that the expectation coefficient is recursively determined based on all past realizations. The starting point $\alpha_{0}$ is an exogenous initial value. This mechanism of beliefs updating is illustrated schematically on figure 6 . This figure shows that the estimated OLS coefficient $\hat{\alpha}_{t}$ is based on past information available up to this period. Workers use this coefficient to form expectations about their future wages $E\left[w_{i t+1}\right]=\hat{\alpha}_{t} y_{i t+1}+\left(1-\hat{\alpha}_{t}\right) w_{i t}$. This is a specific linear form of the theoretical expectation operator $\phi\left(y, w_{0}\right)$. Those workers who are matched with new sufficiently productive employers, use their expectations when bargaining over the wage $w_{i t+1}$. The actual bargained wage can be higher $\left(w_{i t+1}>E\left[w_{i t+1}\right]\right)$ or lower $\left(w_{i t+1}<E\left[w_{i t+1}\right]\right)$ than the expected wage. In period $t+1$ the statistical office collects full data on wages and productivities and uses this information to update the estimated OLS coefficient $\hat{\alpha}_{t+1}$.

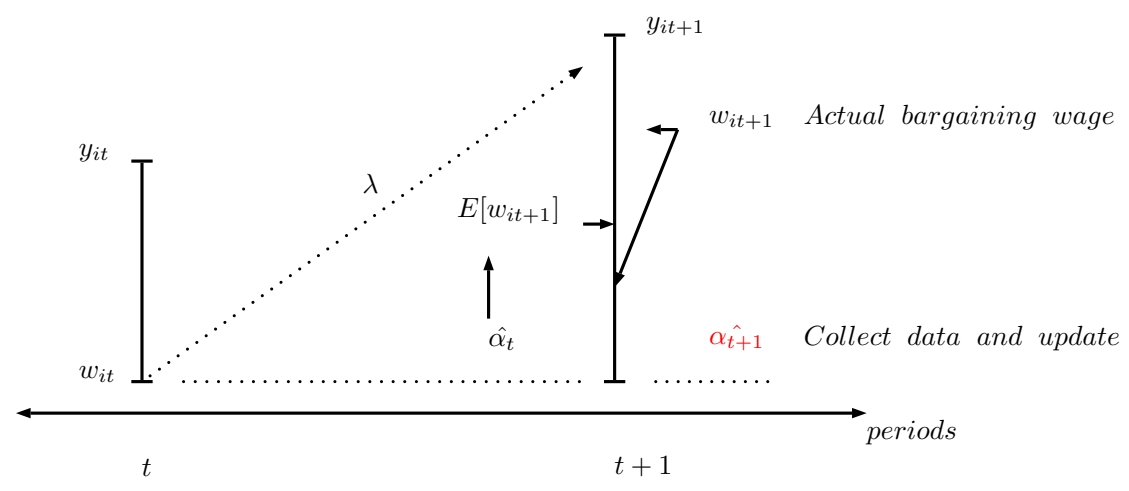

Figure 6: Statistical updating of the expectation parameter $\alpha$

The rest of the simulation refers to workers' transitions between unemployment and jobs. Here we closely follow the mechanism of our analytical model implemented in discrete time. Specifically, in each period $t+1$, workers and firms match randomly with probability $\lambda$ and decide whether they start working together or not. When a worker $i$ and a firm match, they draw a joint productivity level $y_{i t+1}$ from $Q(y)$ productivity distribution randomly. The actual wage $w_{i t+1}$ is bargained between the two as long as the productivity level $y_{i t+1}$ is higher than the worker's current wage $w_{i t}$. They produce output $y_{i t+1}$ in any period afterwords until the job is destroyed (which happens with probability $\delta$ ) or the worker quits the job. We use equation (9) to determine the wage.

In Figure 7, workers' actions and transitions are illustrated as a decision tree and the status of the $i^{\text {th }}$ worker at time period $t$ is denoted by $S_{i t}$. Workers can be either unemployed or employed, and the corresponding status index $S_{i t}$ is 0 and 1 respectively. Unemployed and employed workers receive job offers at the same exogenous rate $\lambda$. While unemployed workers will accept the job offer immediately, employed workers will accept it if the joint productivity level of the new match is higher than the worker's current wage. If so, the worker makes a jobto-job transition. In contrast, when worker's productivity in the new match is smaller than the current wage, the worker will remain at his/her current job. The pseudo-code of the simulation 
is provided in the appendix.

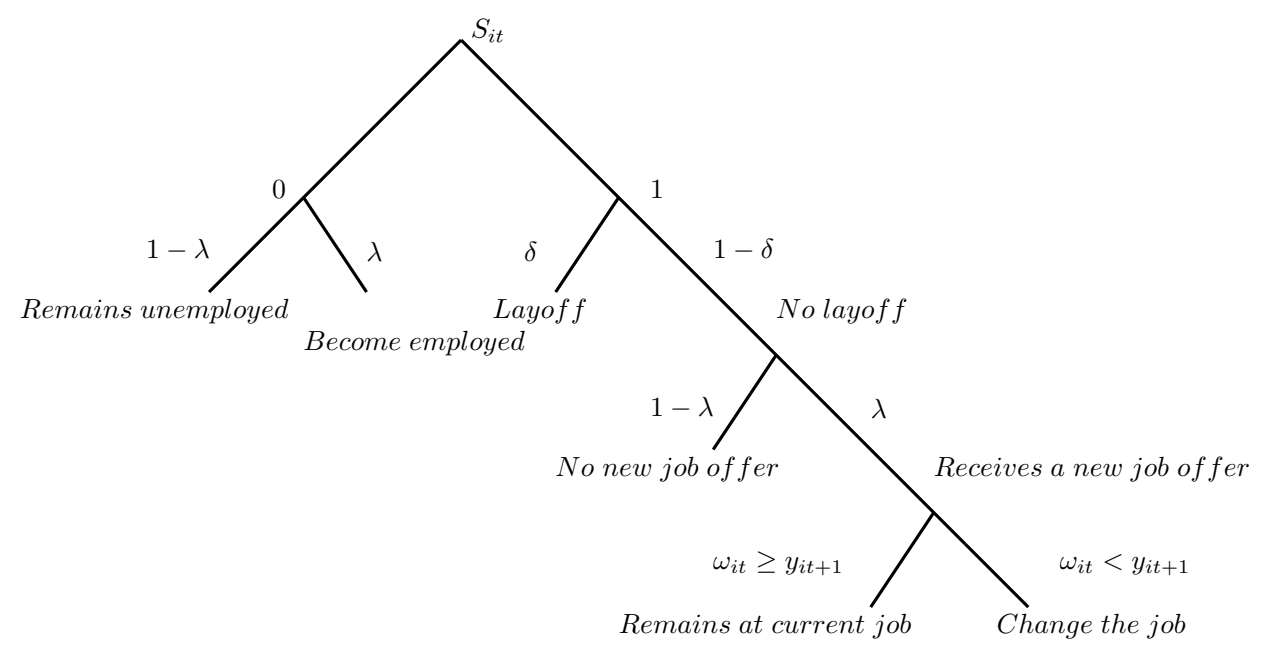

Figure 7: Workers' transitions

\subsection{Numerical results}

In this section we present our numerical results for the mechanism of statistical learning. We consider an economy consisting of $n=100$ workers and simulate the economy over $T=250$ time periods. The key parameters are $\lambda=0.45, \delta=0.05$ and $\gamma=1$ as before. We consider two initial expectation coefficients $\alpha_{0}=0.5$ and $\alpha_{0}=0.75$ to investigate the impact of initial conditions. One remaining parameter to be determined is the bargaining power $\beta$. Following Petrongolo and Pissarides (2001) and Pissarides (2009) we focus on the case $\beta=0.5$, but we also consider a smaller $(\beta=0.4)$ and a larger $(\beta=0.6)$ value of the bargaining power. This gives rise to 6 different scenarios depending on $\alpha_{0}$ and $\beta$. Although workers are homogeneous in terms of their expectation formation, they become heterogeneous over time with respect to their wages and productivities starting from identical initial conditions. We simulate the model 10 times in each scenario with different seeds of the random number generator in order to account for the non-deterministic features of the model.

Next we describe our results. Consider first scenarios $1 A$ and $1 B$ where the bargaining power $\beta$ is equal to 0.4 but there are different starting values for $\alpha_{0}$. Figure 8 presents 10 different paths of the estimated expectation coefficient $\hat{\alpha}_{t}^{r}$. One path corresponds to one simulation run $r$. The left panel refers to scenario $1 A$ with the initial value $\alpha_{0}=0.5$. The right panel illustrates scenario $1 B$ with $\alpha_{0}=0.75$. Further, we calculated average values of $\hat{\alpha}_{t}^{r}\left(\sum_{r} \hat{\alpha}_{t}^{r} / 10\right)$ over 10 runs in each scenario. We can see that in the first scenario the average expectation coefficient quickly converges to the value 0.584 . In the second scenario $1 B$ the average expectation coefficient converges to 0.586 , however, their difference is not statistically significant. Based on this result we conclude that there is no persistent bias associated with the starting value $\alpha_{0}$ and calculate an average $\bar{\alpha}_{t}=\sum_{r} \hat{\alpha}_{t}^{r} / 20$ over 20 runs, which is equal to 0.585 . We call this scenario 1 . This average is illustrated on the left panel of figure 10, bottom curve.

Next we repeat our analysis for scenarios 2 and 3 where the bargaining power is $\beta=0.5$ and $\beta=0.6$ respectively. 20 paths of the estimated coefficient $\hat{\alpha}_{t}^{r}$ are presented in figure 9 , while the corresponding average values $\bar{\alpha}_{t}$ over 20 runs are again illustrated on figure 10 . All three scenarios 

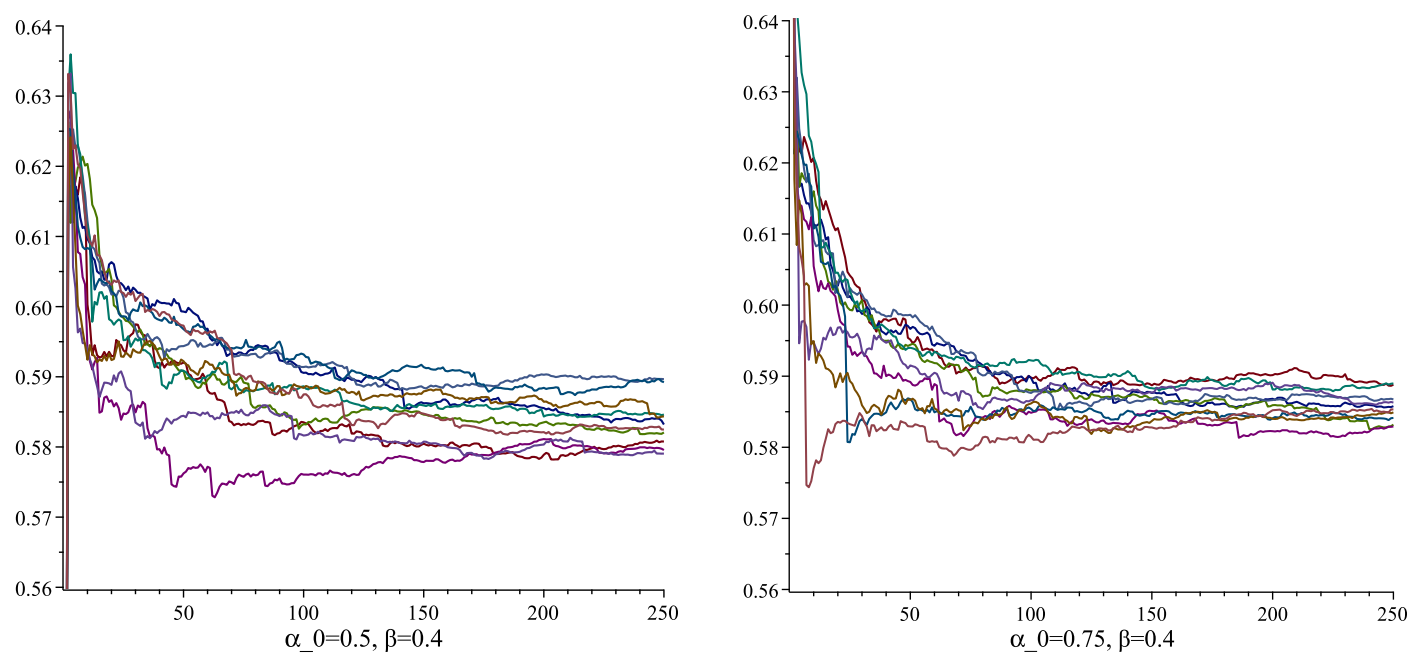

Figure 8: Convergence: $\beta=0.4$

reveal the same pattern: the estimated expectation coefficient $\bar{\alpha}_{t}$ is relatively high in the first 100 time periods but as time passes workers update their estimates and it gradually converges to the steady state value. The process of convergence builds on the fact that agents' current expectations affect the actual outcomes, and the actual outcomes affect their expectations in the next period. Thus if many workers underestimated their actual wages and were positively surprised, the expectation is revised upward in the next period. The opposite is true when many workers overestimated their actual wages and were disappointed by the bargaining outcome. In the steady state the sum of squared errors is minimized, so that there is only a minimal updating of expectations. Note that the outcomes in the steady state are "self-confirming" in the sense that the data that people see lead people to take actions that reproduce the data they see (Rotemberg (2017)). Figure 10 reveals that already after 100 time periods all three curves flatten out.

The right panel of this figure shows average wages for each scenario, which we calculated as: $\bar{w}_{t}=\sum_{r} \bar{w}_{t}^{r} / 20$, where $\bar{w}_{t}^{r}$ is the average wage of employed workers in run $r$ and time period $t$. We can see a similar pattern with the average wages flattening out after period 100. For a more rigorous statistical conclusion we regressed average wages $\bar{w}_{t}$ on a time trend over restricted time periods $\{\bar{t} . .250\}$ with $\bar{t}$ taking values $\{0,50,100,115 \ldots 160\}$. The slope coefficients from regression $\bar{w}_{t}=\mu_{0}+\mu t+\varepsilon_{t}$ are presented in table 9 in the appendix. Initially the time trend is significantly positive in all three scenarios but already for $\bar{t}=100$ it becomes insignificant in scenarios 1 and 2. It takes about 150 time periods in scenario 3 . The fact that the time trend becomes smaller and insignificant in all three scenarios reflects convergence to the steady state. In the following analysis we only use the last 150 time periods for estimating average values of endogenous variables in the steady state. The average expectation coefficient for every scenario is then calculated as $\bar{\alpha}=\sum_{t} \bar{\alpha}_{t} / 150$. These average values are summarized in table 1. The corresponding standard deviations of means over 20 runs are reported in parentheses. Following Evans and Honkapohka (2001) we refer to this steady state as a Restricted Perceptions Equilibrium since workers use recursive OLS learning and correctly perceive the correlation between productivities and wages $(\alpha)$ without fully understanding the actual bargaining process. Moreover, in the equilibrium there is consistency between the workers beliefs and the actual 
outcomes meaning that $\alpha=\bar{\alpha}(\alpha)$.
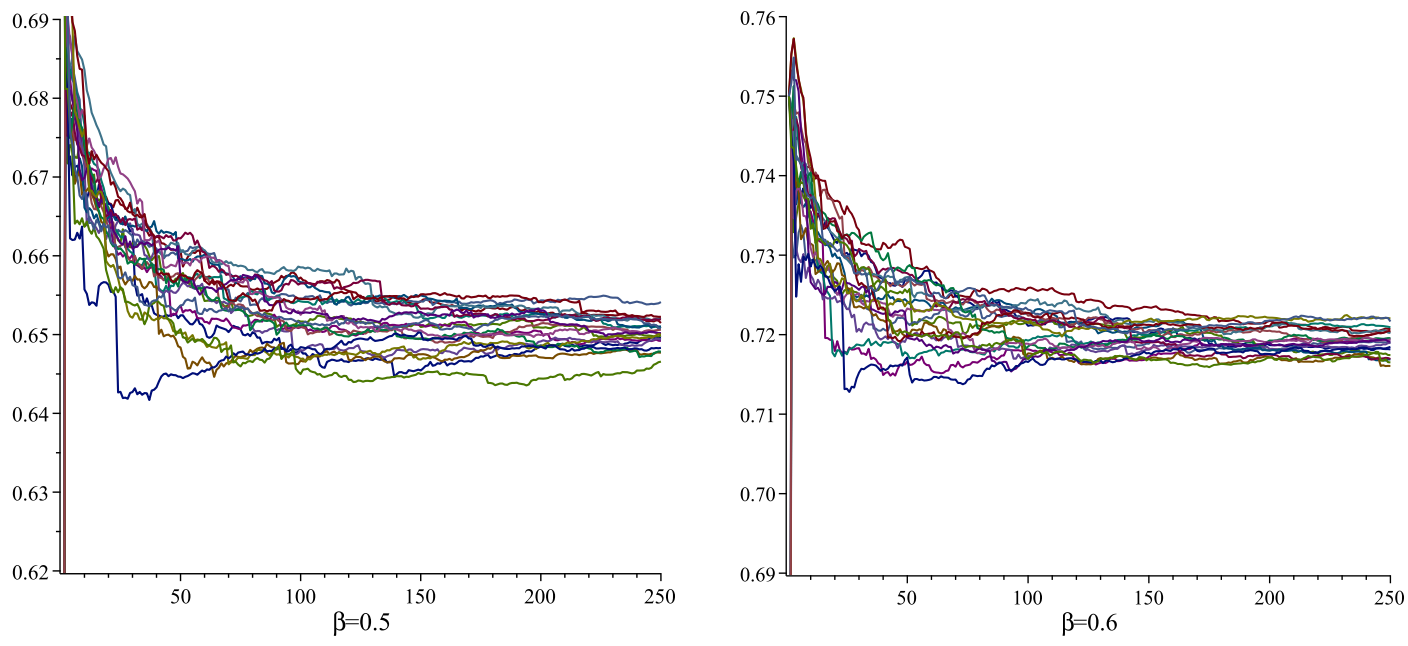

Figure 9: Convergence: $\beta=0.5$ and $\beta=0.6$

Table 1 shows that the estimated expectation coefficient $\bar{\alpha}$ is increasing with the bargaining power $\beta$. For example, in the second scenario when $\beta=0.5$ the estimated $\bar{\alpha}$-coefficient is equal to 0.6508 . In the third scenario when $\beta=0.6$ the estimated $\bar{\alpha}$-coefficient is equal to 0.7195 . This pattern reveals an important property of the model. The gap between the bargaining power parameter $\beta$ and the estimated slope parameter $\bar{\alpha}$ in the wage regression are moving closer to each other with a higher bargaining power. This trend is very intuitive, since a full bargaining power of workers $\beta=1$ would be associated with $\bar{\alpha}=1$. This is the case when workers receive wages equal to their productivity, so the previous wage $w_{0}$ doesn't have any impact on the negotiation outcome. Hence an increasing pattern of $\bar{\alpha}$ with the bargaining power reflects a diminishing role of the worker's outside option.
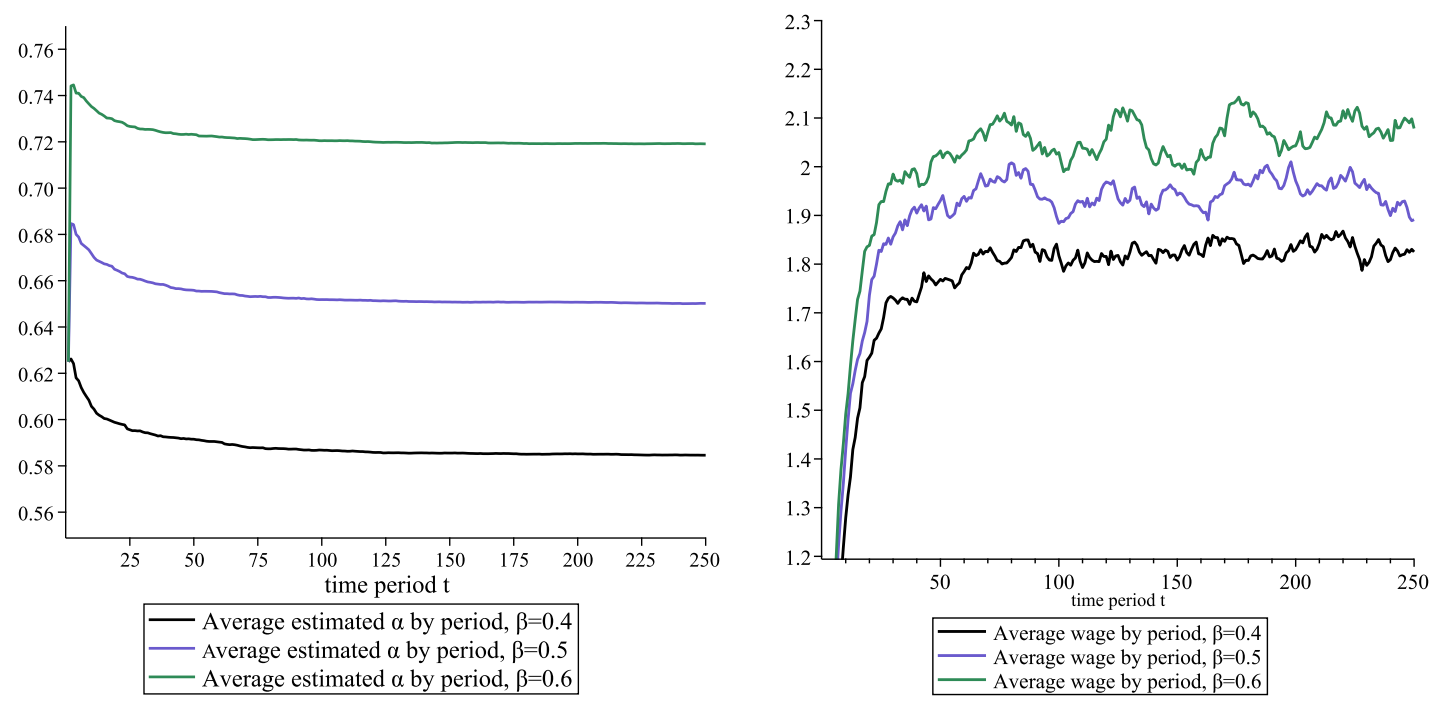

Figure 10: Left panel: Average values of $\bar{\alpha}_{t}$ over 20 runs. Right panel: average wages $\bar{w}_{t}$ over 20 runs

In the next step, we analyze the quality of workers' forecasts in the model. For this purpose we plotted predicted and actual wages on figures 11-12 taking realizations from the last period 


\begin{tabular}{lccc}
\hline \hline \multirow{2}{*}{ Initial Values } & \multicolumn{3}{c}{ Bargaining power } \\
\cline { 2 - 4 } & $\beta=0.4$ & $\beta=0.5$ & $\beta=0.6$ \\
\hline \hline$\alpha_{0}=0.5$ & 0.5844 & 0.6509 & 0.7194 \\
$(10$ runs $)$ & $(0.003)$ & $(0.002)$ & $(0.001)$ \\
$\alpha_{0}=0.75$ & 0.5861 & 0.6507 & 0.7196 \\
$(10$ runs $)$ & $(0.002)$ & $(0.002)$ & $(0.001)$ \\
\hline \hline$(20$ runs $)$ & 0.5853 & 0.6508 & 0.7195 \\
& $(0.003)$ & $(0.002)$ & $(0.001)$ \\
\hline \hline
\end{tabular}

Table 1: Average convergence coefficient: $\gamma=1$

$t=250$ in all 20 runs. These figures reveal that workers make small forecasting mistakes when bargaining with low productivity employers $\left(y_{i t}-w_{i t-1}<1\right)$ but their forecasting precision is worse when the net productivity of the new match is substantially larger than 1 . For example, on the left panel of figure 11, we can see a worker in a match with the net productivity equal to $y_{i t}-w_{i t-1}=7$. This worker expected a net wage gain equal to $E\left[w_{i t}\right]-w_{i t-1}=4.09$ but the actual net wage was well below the expectation $\left(w_{i t}-w_{i t-1}=3.53\right)$. At this point it is important to note that the probability of being in a match with the net productivity gain equal to or larger than $y_{i t}-w_{i t-1}=7$ is extremely low given that match qualities are distributed according to the exponential distribution $1-e^{-\gamma y}$ and $\gamma=1$. For example, if we take some unemployed worker with $w_{i t-1}=0$, this probability is equal to $0.1 \%$. This means that low productivity realizations are much more frequent than high productivities, so the slope of the linear wage regression converges to the point $\bar{\alpha}$ where there is a high quality of forecasting for the majority of workers in low productivity jobs, while rare productivity outliers are less important.
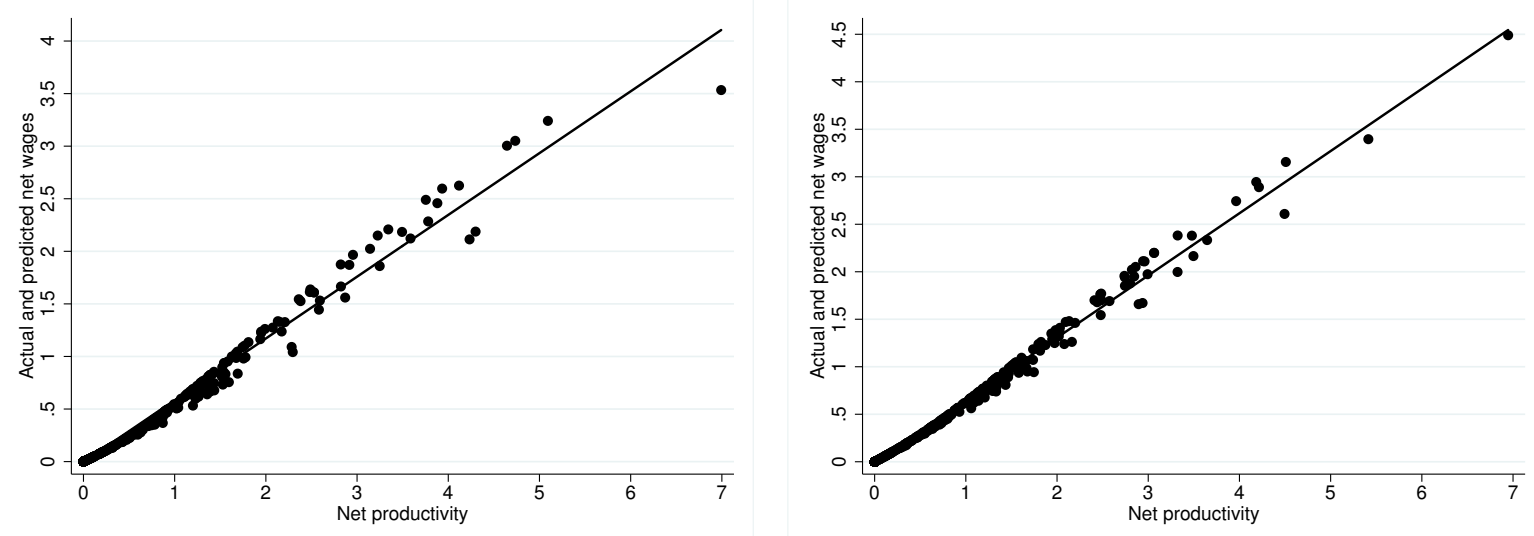

Figure 11: Left panel: Linear regression for $\beta=0.4$. Right panel: Linear regression for $\beta=0.5$

In addition, table 2 shows OLS estimation of wages in the last period $t=250$. Even though 100 workers in 20 runs produce 2000 data points, wage regressions are only based on workers changing jobs and moving up the wage ladder. This leaves us with 237-292 observations depending on the exact scenario. We can see that the overall goodness-of-fit measured by the 
$R^{2}$-coefficient is very high. The reason is that even though the actual wage curve is convex in the productivity $y$, it is close to being flat and has low curvature for our parameter values (see figure 5 ). More important is the observation that the quality of forecasting is improving with a higher bargaining power $\beta$. The reason is that the higher bargaining power always leads to higher wages, but the productivity distribution is the same in all three scenarios, so the average bargaining surplus is smaller in the scenarios with a higher bargaining power, which makes it easier to forecast wages. Finally, in all three scenarios we estimated one restricted (without the intercept) and one unrestricted regression. We can see that the intercepts are significantly different from zero from a statistical perspective, but they are small in absolute terms and decreasing with the bargaining power. At the same time the estimated slope coefficients in restricted regressions in table 2 (which are based only on the data from period $t=250$ ) are remarkably close to the average estimates in table 1 (based on pooled data from periods $t=101 \ldots 250$ ). This confirms once more the result that our simulation reaches an equilibrium after $t=100$. The right panel on figure 12 compares the three regression lines across scenarios and shows that the slope coefficient of the wage regression is increasing with the bargaining power.
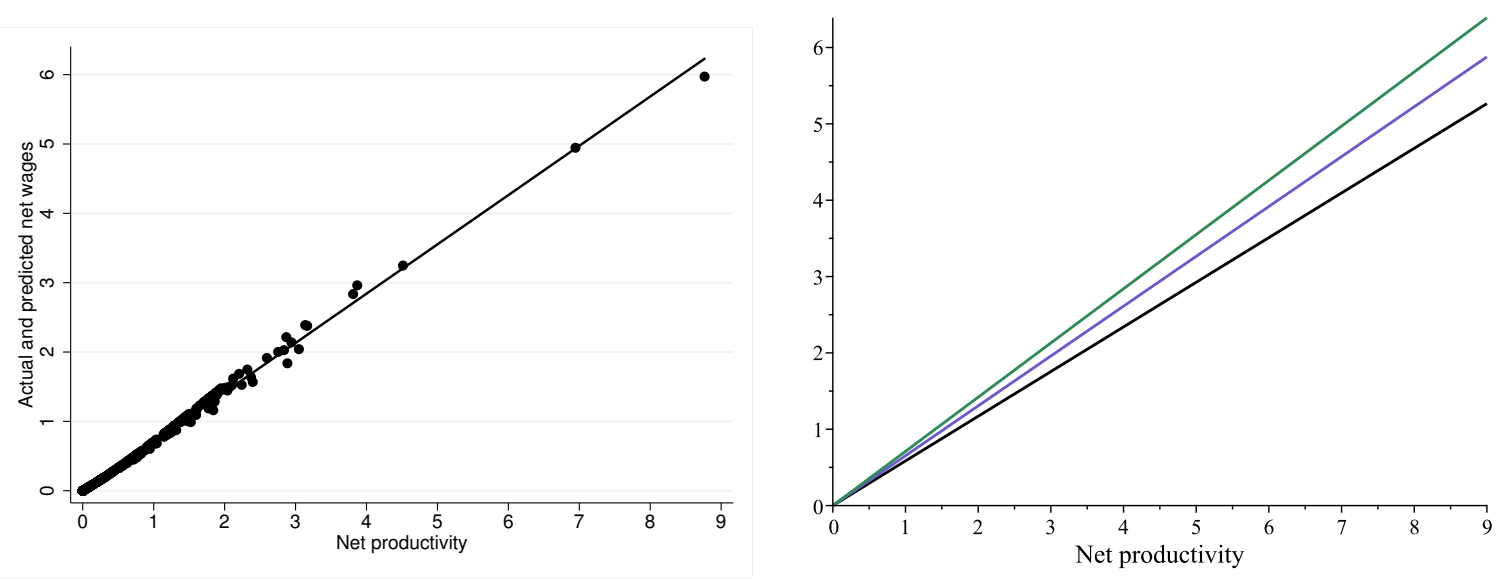

Figure 12: Left panel: Linear regression for $\beta=0.6$. Right panel: Predicted wage differences comparison

\begin{tabular}{lcc|cc|cc}
\hline \hline Variable & \multicolumn{2}{c|}{$\beta=0.4$} & \multicolumn{2}{c|}{$\beta=0.5$} & \multicolumn{2}{c}{$\beta=0.6$} \\
& Unrestr. & Restr. & Unrestr. & Restr. & Unrestr. & Restr. \\
\hline \hline Slope & 0.587 & 0.585 & 0.654 & 0.653 & 0.712 & 0.710 \\
& $(0.001)$ & $(0.001)$ & $(0.001)$ & $(0.001)$ & $(0.001)$ & $(0.001)$ \\
Intercept & -0.004 & & -0.003 & & -0.001 & \\
& $(0.001)$ & & $(0.001)$ & & $(0.000)$ & \\
\hline \hline Nr. of obs. & 292 & 292 & 290 & 290 & 237 & 237 \\
$R^{2}$ & 0.987 & 0.988 & 0.994 & 0.994 & 0.997 & 0.997 \\
\hline \hline
\end{tabular}

Table 2: OLS wage regressions for different scenarios

\subsection{Unemployment rates and wage distributions}

In this section we analyze the macroeconomic properties of the model. Our specific focus is on the equilibrium unemployment and wage inequality among workers. Since our model is 
implemented in the partial equilibrium framework both transition rates $\delta$ and $\lambda$ are exogenous. Moreover, unemployed workers never reject job offers in our setting. So the outflow of workers from unemployment is equal to $\lambda u$ and the inflow is given by $\delta(1-u)$. Thus the steady state unemployment rate is equal to $\delta /(\delta+\lambda)$. Our choice of parameters $\delta=0.1$ and $\lambda=0.45$ implies that the unemployment rate is equal to $10 \%$. Table 3 shows the calculated average unemployment rates in all simulation scenarios. These numbers are based on the average unemployment rate in the last 150 periods of every run. In all scenarios the steady state unemployment rate is not statistically different from $10 \%$.

\begin{tabular}{lccc}
\hline \hline \multirow{2}{*}{ Initial Values } & \multicolumn{3}{c}{ Bargaining power } \\
\cline { 2 - 4 } & $\beta=0.4$ & $\beta=0.5$ & $\beta=0.6$ \\
\hline \hline$\alpha_{0}=0.5$ & 0.0985 & 0.1012 & 0.0988 \\
$(10$ runs $)$ & $\left(0.0055^{*}\right)$ & $\left(0.0049^{*}\right)$ & $\left(0.0051^{*}\right)$ \\
$\alpha_{0}=0.75$ & 0.10 & 0.1006 & 0.0986 \\
$(10$ runs $)$ & $\left(0.0046^{*}\right)$ & $\left(0.0041^{*}\right)$ & $\left(0.0049^{*}\right)$ \\
\hline \hline$(20$ runs $)$ & 0.0995 & 0.1009 & 0.0987 \\
& $\left(0.0049^{*}\right)$ & $\left(0.0044^{*}\right)$ & $\left(0.0049^{*}\right)$ \\
\hline \hline
\end{tabular}

Significance level: ${ }^{*} p<0.05$

Table 3: Unemployment rate $: u=0.1$ is theoretical value

Next we turn to the characterization of the equilibrium wage distributions. Empirical evidence shows that typical wage distributions are hump-shaped and positively skewed (Neal and Rosen (2000), Mortensen (2003); Christensen et al (2005)). First, we consider the limiting case of the wage distribution when $\beta=1$. This is a standard model of on-the-job search based on the framework developed in Burdett-Mortensen (1998). It is the case when workers obtain their productivity, fully foresee their future wages and there are no inefficient transitions. According to Burdett and Mortensen (1998) the equilibrium wage distribution in this case is given by:

$$
g(w)=\frac{\delta(\delta+\lambda) q(w)}{(\delta+\lambda(1-Q(w)))^{2}} \quad \text { where } q(w)=\gamma e^{-\gamma(w-z)} \text { and } Q(w)=1-e^{-\gamma(w-z)}
$$

When productivity realizations have the exponential distribution, we can show that $g(w)$ is hump-shaped with a unique mode on the distribution support. On the one hand, productivity realizations have a decreasing exponential density with most realizations in the left part of the distribution. On the other hand, workers climb the wage/productivity ladder by changing employers. However, climbing the ladder becomes more difficult the higher the wage of the worker, since productivity realizations above the current wage become more and more scarce. Thus the majority of workers climbs quickly to the middle range of the wage distribution where the speed of climbing slows down. This explains the hump-shape of the equilibrium wage density. 
The unique mode of the distribution can be obtained as:

$$
q^{\prime}(w)(\delta+\lambda(1-Q(w)))=-2 \lambda q^{2}(w)
$$

Inserting $q(w)$ and $Q(w)$ corresponding to the exponential distribution we find that the mode is equal to $w_{M}=-\frac{1}{\gamma} \ln \frac{\delta}{\lambda}$. With the benchmark parameters described above we get $w_{M}=2.19$. So the theoretical wage density in the limiting case when $\beta=1$ has a unique maximum at 2.19. Next we derive the average wage $(z=0)$ :

$$
\delta(\delta+\lambda) \int_{0}^{\infty} \frac{w \gamma e^{-\gamma w}}{\left(\delta+\lambda e^{-\gamma w}\right)^{2}} d w=\frac{\delta+\lambda}{\gamma \lambda}[\ln (\delta+\lambda)-\ln \delta]
$$

For our parameter values the average wage is equal to 2.5584. The fact that the mean is larger than the mode is a first indication for the positive skewness of the density. Indeed, the skewness of the distribution is equal to 0.82 (with the standard deviation $\sigma=1.5$ ). This shows that the theoretical wage density when $\beta=1$ is unimodal and positively skewed. What can we say about the equilibrium wage distributions in the other cases when the bargaining power is less than 1 ?

The corresponding wage histograms from period $t=250$ over 20 runs are illustrated on figures 13-14. The average wages over the last 150 periods and 20 runs are calculated as $\bar{w}=$ $\sum_{t} \bar{w}_{t} / 150$ and summarized in table 4 . In all three scenarios we approximate the empirical wage distributions with a Gaussian kernel density function. The three densities and the analytical wage distribution for $\beta=1$ are plotted and compared on the right panel of figure 14 .
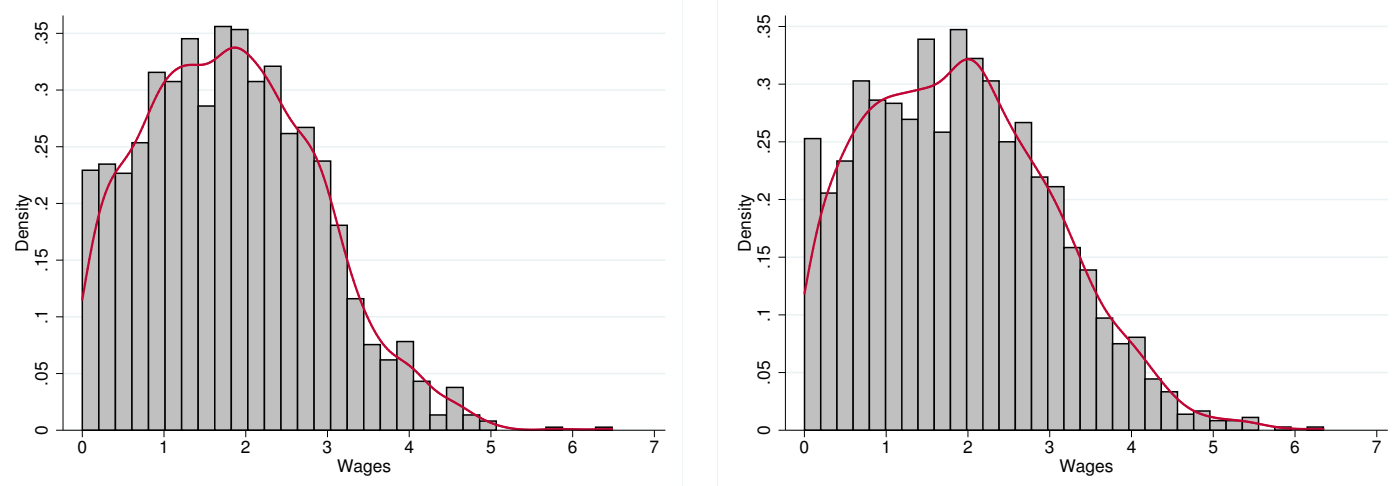

Figure 13: Wage histogram and density: Left panel: $\beta=0.4, \sigma=1.06, s=0.39$. Right panel: $\beta=0.5, \sigma=1.13, s=0.43$

We can see that the average wage is gradually increasing with the bargaining power from 1.8261 when $\beta=0.4$, to 1.9456 when $\beta=0.5$ and finally it is 2.0632 for $\beta=0.6$. This was already illustrated on figure 10. In addition, we know that the upper bound for the average wage is equal to 2.5584 when $\beta=1$. The wage density is shifting to the right as the workers' bargaining power is increasing and approaching the analytical wage distribution $g(w)$ in the limit. Moreover, the dispersion of the wage distribution is also increasing indicating higher wage inequality. For example, the standard deviation $\sigma$ is equal to 1.06 when $\beta=0.4$, it is 1.13 when $\beta=0.5$ and 1.19 in the third scenario when $\beta=0.6$. Recall that in the limiting case of $\beta=1$ the standard deviation is equal to 1.5 . This highlights the fact that a higher individual bargaining power of workers is associated with higher wage inequality in our model. At the same 

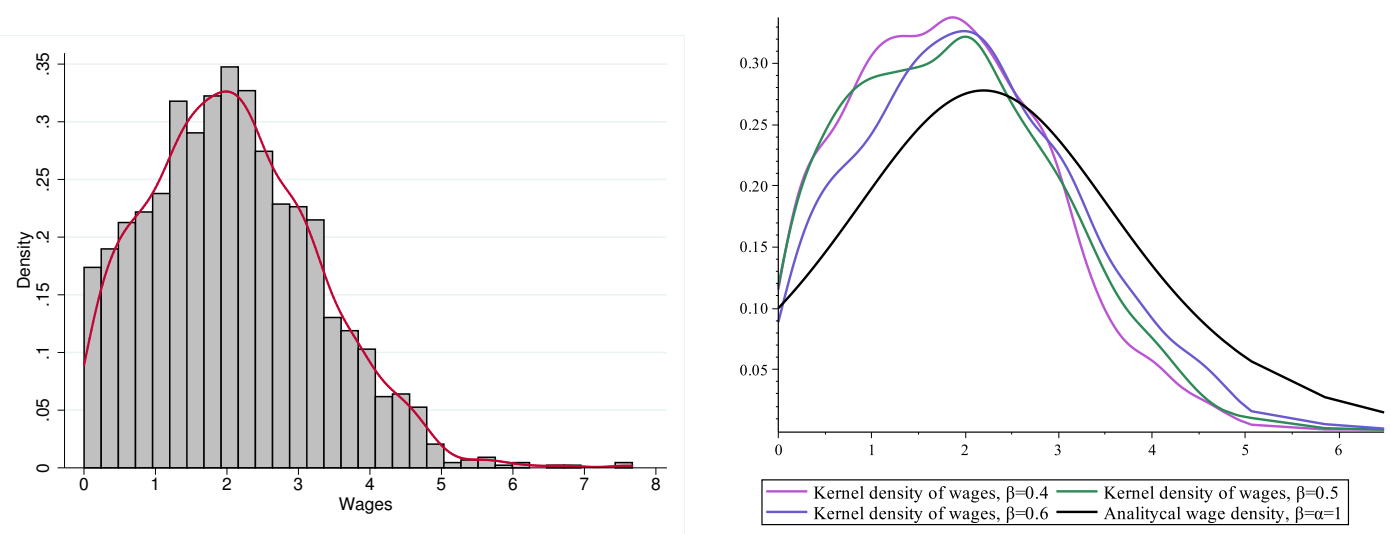

Figure 14: Left panel: Wage histogram and density for $\beta=0.6, \sigma=1.19, s=0.52$. Right panel: Comparison, statistics for the analytical wage density $\sigma=1.50, s=0.82$

time the skewness of the distribution is also increasing indicating that the right tail of the wage distribution is spreading to the right and getting longer. This effect can also be observed on the corresponding wage histograms. Whereas the highest simulated wage in the first scenario is equal to 6.48 , it is already 7.67 in the third scenario when $\beta=0.6$. Overall, we can conclude that the simulated wage distributions are unimodal and positively skewed inline with the empirical evidence. Furthermore, wage dispersion and the skewness of the distribution are both increasing with the individual bargaining power of workers.

\begin{tabular}{llll}
\hline \hline \multirow{2}{*}{ Initial Values } & \multicolumn{3}{c}{ Bargaining power } \\
\cline { 2 - 4 } & $\beta=0.4$ & $\beta=0.5$ & $\beta=0.6$ \\
\hline \hline$\alpha_{0}=0.5$ & 1.8349 & 1.9348 & 2.0694 \\
$(10$ runs $)$ & $(0.042)$ & $(0.064)$ & $(0.065)$ \\
$\alpha_{0}=0.75$ & 1.8174 & 1.9563 & 2.0569 \\
$(10$ runs $)$ & $(0.042)$ & $(0.038)$ & $(0.040)$ \\
\hline \hline$(20$ runs $)$ & 1.8261 & 1.9456 & 2.0632 \\
& $(0.050)$ & $(0.051)$ & $(0.052)$ \\
\hline \hline
\end{tabular}

Table 4: Average wages: $\gamma=1$

In the next step we investigate the link between the bargaining power $\beta$ and the incidence of job-to-job transitions. Since employed workers only consider their personal wage improvements when moving between jobs, job-to-job transitions can be either efficient or inefficient. The jobto-job transition is efficient if the newly matched firm's productivity level is higher than that of the current employer of the worker, otherwise it is inefficient (recall figure 2). Consider first the limiting case when $\beta=1$. The measure of employees earning wage $w$ is given by $\operatorname{eg}(w)$, where $e=\lambda /(\delta+\lambda)$ is the employment rate. These workers are matched with a new employer at rate $\lambda$. With probability $(1-Q(w))$ the productivity of the new match is higher than the current wage of the worker $w$ which leads to the job change. So the measure of workers employed at wage $w$ and moving up in the wage ladder is $\operatorname{eg}(w) \lambda(1-Q(w))$. Integrating over all workers and 
dividing by the total employment $e$ we get the average fraction of employees changing the job. The exponential distribution of productivities yields the following result:

$\int_{0}^{\infty} g(w) \lambda(1-Q(w)) d w=\lambda \delta(\delta+\lambda) \gamma \int_{0}^{\infty} \frac{e^{-2 \gamma w}}{\left(\delta+\lambda e^{-\gamma w}\right)^{2}} d w=\frac{\delta}{\lambda}(\delta+\lambda)[\ln (\delta+\lambda)-\ln (\delta)]-\delta$

With our parameter values this gives a fraction of employees changing jobs equal to $7.8 \%$. It is remarkable that this fraction is independent of parameter $\gamma$, that is the shape of the productivity distribution $Q(y)$ is irrelevant for the fraction of job-to-job movers. The same result is illustrated in Hornstein et al. (2011) (equation 15). In fact they show that the fraction of job-to-job movers as well as the ratio between the mean wage and the (non-zero) reservation wage are the same in the Burdett and Mortensen (1998) framework irrespective of the distribution $Q(y)$.

From an empirical perspective Hornstein et al. (2011) report that the average monthly jobto-job flow in the United States varies between $2.2 \%$ and $3.2 \%$ of employment. This is equivalent to quarterly numbers between $6.6 \%$ and $9.6 \%$. These numbers are similar to the outcome of our simulation presented in table 5 . When $\beta=0.4$, the average fraction of employees moving to better paid jobs is equal to $11.17 \%$. It is decreasing with a higher bargaining power and equal to $10.44 \%$ when $\beta=0.5$. Further, it falls down to $9.64 \%$ in the third scenario. We already know that in the limiting case $\beta=1$ the lower bound for the fraction of job-to-job movers is $7.8 \%$.

\begin{tabular}{lccc}
\hline \hline \multirow{2}{*}{ Initial Values } & \multicolumn{3}{c}{ Bargaining power } \\
\cline { 2 - 4 } & $\beta=0.4$ & $\beta=0.5$ & $\beta=0.6$ \\
\hline \hline$\alpha_{0}=0.5$ & 0.1119 & 0.1051 & 0.0971 \\
$(10$ runs $)$ & $(0.0038)$ & $(0.0033)$ & $(0.0035)$ \\
$\alpha_{0}=0.75$ & 0.1114 & 0.1037 & 0.0957 \\
$(10$ runs $)$ & $(0.0035)$ & $(0.0019)$ & $(0.0027)$ \\
\hline \hline$(20$ runs $)$ & 0.1117 & 0.1044 & 0.0964 \\
& $(0.0036)$ & $(0.0026)$ & $(0.0031)$ \\
\hline \hline
\end{tabular}

Table 5: Workers' job-to-job transitions: $\gamma=1$

At this point it is important to emphasize that not all job-to-job transitions of workers are efficient. To the best of our knowledge there is only one other study that addressed the problem of inefficient transitions in the setting with on-the-job search, this is Flinn et al. (2017). In their model there are two types of firms: one group of firms is always renegotiating wages whenever their workers get an outside offer, another group of firms makes a take-it-or-leave-it wage offer and never renegotiates. Due to the presence of these two firm types it happens that the worker employed in the non-negotiating firm is matched with a less productive bargaining employer, negotiates a higher wage and makes the move. However, Flinn et al. (2017) stress the point that inefficient transitions exist only if both types of firms coexist in the market. Our model is based on the assumption that firms bargain over the wage in the beginning of the employment relationship but don't renegotiate if the worker gets an outside offer. Due to this 
feature inefficient transitions arise in the market when all firms are of the same type and follow the same wage strategy.

Table 6 shows the average number of inefficient transitions expressed as a fraction of all transitions. In the first scenario when the bargaining power is low $(\beta=0.4), 28.29 \%$ of all transitions are inefficient but this fraction is decreasing with the bargaining power down to $23.35 \%$ when $\beta=0.5$ and $19.89 \%$ in the third scenario. In the limiting case when $\beta=1$ all transitions are efficient since wages are equal to the marginal productivities and workers only make the move if their wage is higher with the new employer. This pattern is intuitive. If the bargaining power of workers is low, bargained wages are well below the marginal productivity of the employer, so there is a high probability of $28.29 \%$ that the worker will be matched with a new employer who's productivity is above the current wage of the worker but below the productivity of the current employer. As the bargaining power is increasing the gap between wages and productivities is closing and the probability of inefficient transitions is decreasing.

\begin{tabular}{lccc}
\hline \hline \multirow{2}{*}{ Initial Values } & \multicolumn{3}{c}{ Bargaining power } \\
\cline { 2 - 4 } & $\beta=0.4$ & $\beta=0.5$ & $\beta=0.6$ \\
\hline \hline$\alpha_{0}=0.5$ & 0.2867 & 0.2340 & 0.2003 \\
$(10$ runs $)$ & $(0.009)$ & $(0.015)$ & $(0.010)$ \\
$\alpha_{0}=0.75$ & 0.2792 & 0.2331 & 0.1975 \\
$(10$ runs $)$ & $(0.011)$ & $(0.012)$ & $(0.007)$ \\
\hline \hline$(20$ runs $)$ & 0.2829 & 0.2335 & 0.1989 \\
& $(0.010)$ & $(0.013)$ & $(0.008)$ \\
\hline \hline
\end{tabular}

Table 6: Workers' inefficient transitions: $\gamma=1$

Summarizing the results of this section we can see that a higher individual bargaining power of workers is associated with higher wage inequality in our model. This trend is observed despite the fact that the overall mobility of workers and the fraction of inefficient transitions are decreasing with a higher bargaining power.

\subsection{Robustness check}

In this section we analyze the role of the productivity distribution $Q(y)$ in shaping the market. So far we used an exponential distribution $Q(y)=1-e^{-\gamma y}$ with parameter $\gamma=1$. In our model workers form their expectations by using aggregate data on wages. This means if low productivity matches are very frequent, the sample contains many workers employed at low productivities and low wages. This statistical data may produce pessimistic wage expectations. However, if high productivity matches are very frequent, then the statistical sample will contain many observations with high productivities and high wages. This may lead to more optimistic expectations. This means that, on the one hand, the shape of the productivity distribution could bias the expectations of workers in the steady-state. On the other hand, Hornstein et al. (2011) show that the wage-ladder model of Burdett-Mortensen has a number of properties, 
for which the distribution of wage offers/productivities is irrelevant. One such feature we have already highlighted in the previous section, namely the fact that the fraction of job-to-job movers doesn't depend on parameter $\gamma$. So it is apriori not clear if $\gamma$ has an impact on the expectation coefficient $\alpha$ or not.

In order to answer this question we performed additional simulations with a higher value of $\gamma$ equal to 2 . The average productivity of new matches in this case is equal to 0.5 , which is two times lower compared to the benchmark model. Also the productivity threshold $y^{*}=(k+\lambda) / \lambda \gamma$ is two times lower and equal to 0.565 . At the same time we can see that this shift of the distribution doesn't lead to the relative changes. For example, the fraction of new matches with productivity below the mean is again $P\left\{y<\frac{1}{\gamma}\right\}=1-e^{-\gamma / \gamma}=0.63$ and the fraction of productivity draws below $y^{*}$ remains the same: $P\left\{y<y^{*}\right\}=1-e^{-\gamma y^{*}}=1-e^{-(k+\lambda) / \lambda}=0.68$. For the purpose of this section we restrict our analysis only to the first two scenarios with $\beta=0.4$ and $\beta=0.5$ and the starting value $\alpha_{0}=0.5$. Table 7 shows the average expectation coefficient $\bar{\alpha}$ and the average wages based on the last 150 observations of every run. As expected the average wages are roughly two times smaller compared to the reference case $\gamma=1$. The corresponding wage histograms and kernel densities are illustrated on figure 15 .

\begin{tabular}{lcc||lll}
\hline \hline \multirow{2}{*}{ Variable } & \multicolumn{2}{c|}{ Bargaining power } & Variable & \multicolumn{2}{c}{ Bargaining power } \\
& $\beta=0.4$ & $\beta=0.5$ & & $\beta=0.4$ & $\beta=0.5$ \\
\hline \hline Average $\bar{\alpha}$ & 0.5856 & 0.6500 & Average wage & 0.9099 & 0.9726 \\
& $(0.003)$ & $(0.001)$ & & $(0.020)$ & $(0.014)$ \\
\hline \hline
\end{tabular}

Table 7: Values of endogenous variables in the steady state when $\gamma=2, \alpha_{0}=0.5,10$ runs
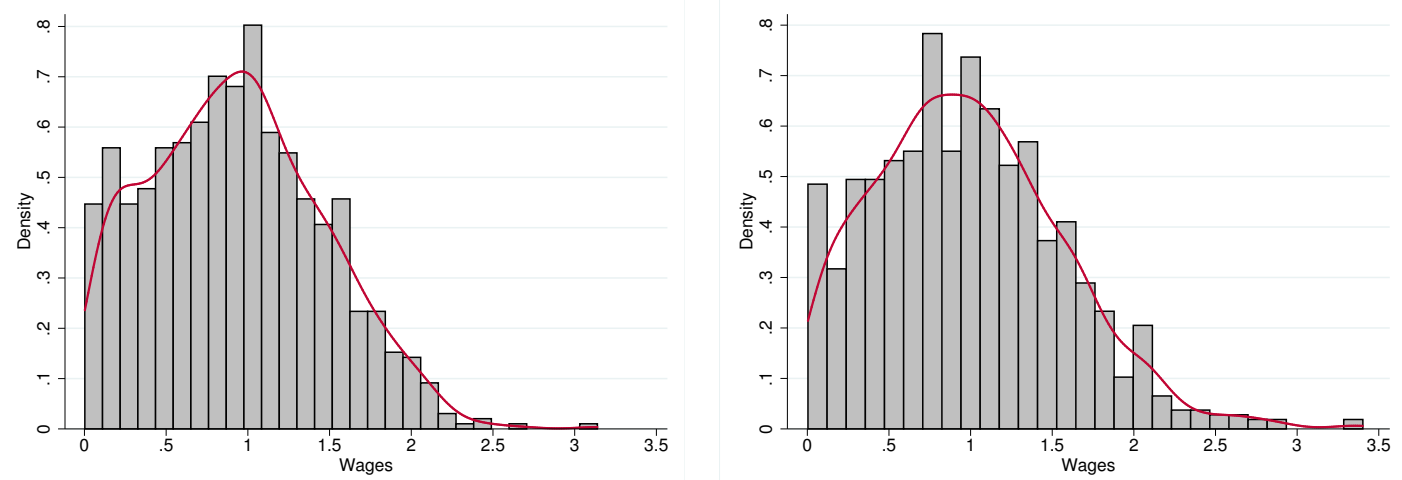

Figure 15: $\gamma=2$. Left panel: Wage histogram and density for $\beta=0.4$. Right panel: $\beta=0.5$

Most important is the result that the average expectation coefficient $\bar{\alpha}$ doesn't change upon the $\gamma$-shift of the productivity distribution. Table 7 shows that $\bar{\alpha}$ is equal to 0.585 for $\beta=0.4$ and it is 0.650 for $\beta=0.5$. These numbers coincide with the reference case reported in table 1 . Thus the shape of the distribution doesn't effect the expectations of workers and our results are invariant to $\gamma$-shifts of the productivity distribution. Figure 16 shows all the runs with $\gamma=2$ in the first two scenarios.

In order to understand this result we have calculated the fraction of job-to-job transitions 

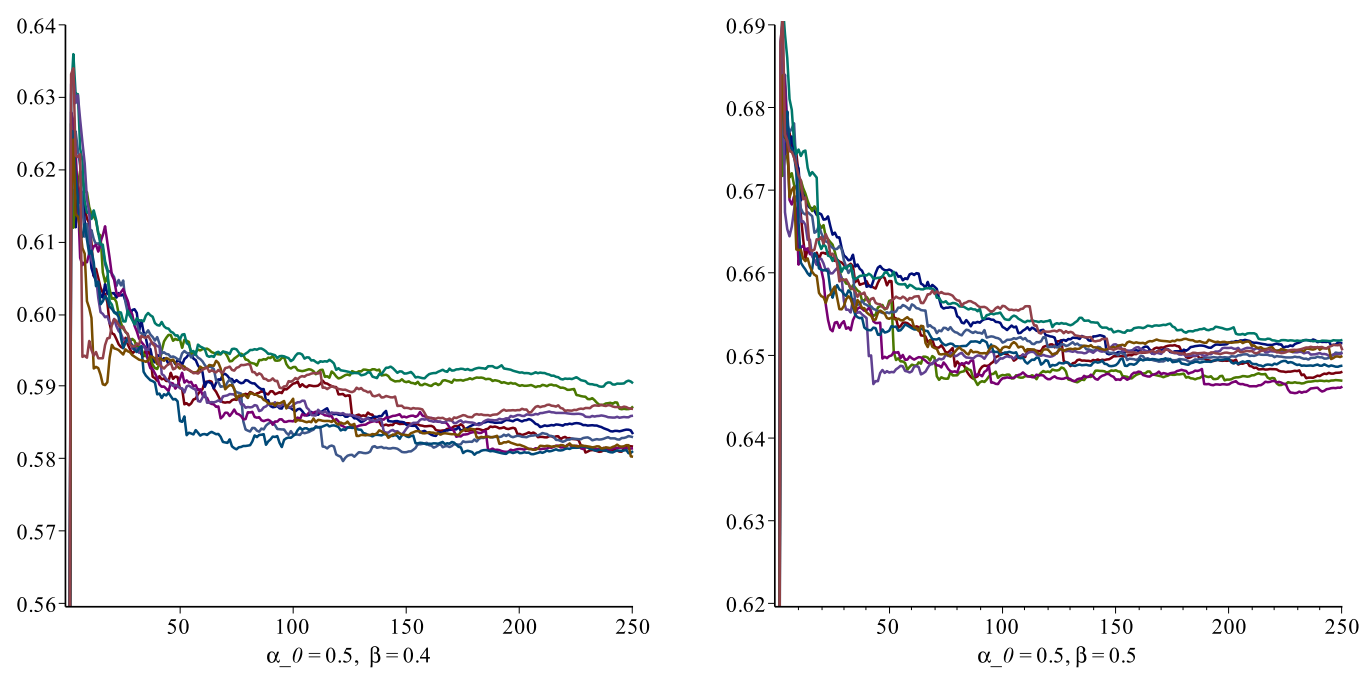

Figure 16: Left panel: $\gamma=2$ and $\beta=0.4$. Right panel: $\gamma=2$ and $\beta=0.5$

and the fraction of inefficient transitions summarized in table 8. We can see that all fractions are similar to those in the reference case. This shows that the shift of the productivity distribution is a nominal change for the model, which is not associated with relative changes, such as the fraction of workers moving between jobs and the fraction of inefficient transitions among them. Also the fraction of workers with productivities below the mean and below the productivity threshold $y^{*}$ doesn't change. Altogether this leads to the fact that the expectation coefficient $\alpha$ is also neutral with respect to the $\gamma$-shifts of the productivity distribution. The question whether a more substantial change of the productivity density going beyond the exponential assumption remains for future research.

\begin{tabular}{lcc||ccc}
\hline \hline \multirow{2}{*}{ Variable } & \multicolumn{2}{c||}{ Bargaining power } & \multirow{2}{*}{ Variable } & \multicolumn{2}{c}{ Bargaining power } \\
& $\beta=0.4$ & $\beta=0.5$ & & $\beta=0.4$ & $\beta=0.5$ \\
\hline \hline Inefficient transitions & 0.2710 & 0.2356 & Job-to-job transitions & 0.1129 & 0.1038 \\
& $(0.012)$ & $(0.010)$ & & $(0.0036)$ & $(0.0028)$ \\
\hline \hline
\end{tabular}

Table 8: Steady-state transitions when $\gamma=2, \alpha_{0}=0.5,10$ runs

\section{Conclusion}

In this paper we develop a search and matching model with heterogeneous firms, on-the-job search, Nash bargaining and simple linear learning mechanism. Workers are homogeneous and seek better paid jobs while they are unemployed or employed. In particular, we consider boundedly rational workers and model the bargaining process as a "black box" meaning that workers have limited foresight and can not perfectly predict the outcome of wage bargaining. Workers in our model behave as economic statisticians and update their beliefs over time as new data becomes available. Specifically, we assume that workers use OLS learning mechanisms and base 
their forecasts on the estimated linear wage regression with the firm's productivity and worker's current wage as regressors. For a restricted set of parameters, we show analytically that the bargaining solution in this setting is unique. We embed this solution into the agent-based simulation which allows us to provide a numerical characterization of the Restricted Perceptions Equilibrium. We use the simulation to record workers' transitions across employers, as well as their wages and productivities. This empirical data is used to estimate the coefficient of the wage regression reflecting an empirical correlation between wages and productivities. We find that the estimated coefficients converge to the steady state values and workers do not make systematic errors on average. So workers' beliefs and the actual outcomes are consistent in the equilibrium. The estimated coefficient on productivity is always higher than the bargaining power parameter, but the difference between the two is decreasing with the bargaining power and vanishes when workers are paid their full productivity. This is the limiting case when workers' expectations are rational. The overall quality of forecasting is very high and increasing in the bargaining power.

Further, we can show that the average wage in the steady-state is increasing in the bargaining power of workers and there is a gradual shift towards the analytical wage distribution in the limiting case when workers are paid their full productivity. At the same time wages become more dispersed and the positive skewness of the wage distribution becomes stronger with a higher bargaining power. One of the most important properties of our model is that it allows to evaluate the extent of inefficient transitions. Our results indicate that a higher bargaining power of workers is associated with a lower overall frequency of job-to-job transitions and a lower fraction of inefficient transitions among them. This sheds some light on the lower jobto-job mobility of workers in countries with strong unionization, like France and Germany and more intensive job-to-job mobility in the US and UK reported in Jolivet et al. (2006). Finally, we show that our results are robust to the shifts of the productivity distribution. In particular, we find that the coefficients of the linear regression used in shaping workers expectations do not change if the average productivity of firms is increased or reduced.

\section{Appendix}

\section{Appendix I}

$$
\begin{aligned}
& r W(w)= w+\lambda \int_{w}^{\bar{y}}(W(\phi(y, w))-W(w)) d Q(y)-\delta(W(w)-U) \\
&= w+\left.\lambda(W(\phi(y, w))-W(w)) Q(y)\right|_{w} ^{\bar{y}}-\lambda \int_{w}^{\bar{y}} Q(y) W^{\prime}(\phi(y, w)) \phi_{y}^{\prime}(y, w) d y-\delta(W(w)-U(\bar{\jmath} 1) \\
&= w+\lambda(W(\phi(\bar{y}, w))-W(w))-\lambda \int_{w}^{\bar{y}} Q(y) W^{\prime}(\phi(y, w)) \phi_{y}^{\prime}(y, w) d y-\delta(W(w)-U) \\
&= w+\lambda \int_{w}^{\phi(\bar{y}, w)} W^{\prime}(x) d x-\lambda \int_{w}^{\phi(\bar{y}, w)} Q\left(\phi^{-1}(x, w)\right) W^{\prime}(x) d x-\delta(W(w)-U) \\
&= w+\lambda \int_{w}^{\phi(\bar{y}, w)}\left[1-Q\left(\phi^{-1}(x, w)\right)\right] W^{\prime}(x) d x-\delta(W(w)-U) \\
& r W^{\prime}(w)=1-\lambda(1-Q(w)) W^{\prime}(w)+\lambda(1-Q(\bar{y})) W^{\prime}(\phi(\bar{y}, w)) \phi^{\prime}(\bar{y}, w) \\
& \quad-\quad \lambda \int_{w}^{\phi(\bar{y}, w)} q\left(\phi^{-1}(x, w)\right) \frac{\partial \phi^{-1}(x, w)}{\partial w} W^{\prime}(x) d x-\delta W^{\prime}(w)
\end{aligned}
$$


Given that $Q(\bar{y})=1$ we get:

$$
(r+\delta+\lambda(1-Q(w))) W^{\prime}(w)=1-\lambda \int_{w}^{\phi(\bar{y}, w)} q\left(\phi^{-1}(x, w)\right) \frac{\partial \phi^{-1}(x, w)}{\partial w} W^{\prime}(x) d x
$$

Proof of proposition 1.

$$
\begin{aligned}
W(w) & =\left(k e^{\gamma(w-z)}+\lambda\right)^{\frac{1-\alpha}{\alpha}} \int_{z}^{w} \frac{(\alpha-\gamma(1-\alpha) x)}{\alpha\left(k+\lambda e^{-\gamma(x-z)}\right)}\left(k e^{\gamma(x-z)}+\lambda\right)^{-\frac{(1-\alpha)}{\alpha}} d x \\
& -\left(k e^{\gamma(w-z)}+\lambda\right)^{\frac{1-\alpha}{\alpha}} \frac{\gamma(1-\alpha) \delta U}{\alpha} \int_{z}^{w} e^{\gamma(x-z)}\left(k e^{\gamma(x-z)}+\lambda\right)^{-\frac{1}{\alpha}} d x+\left(k e^{\gamma(w-z)}+\lambda\right)^{\frac{1-\alpha}{\alpha}} C \\
& =A(w)+\left.\frac{\delta U}{k}\left(k e^{\gamma(w-z)}+\lambda\right)^{\frac{1-\alpha}{\alpha}}\left(\left(k e^{\gamma(x-z)}+\lambda\right)^{\frac{-(1-\alpha)}{\alpha}}\right)\right|_{z} ^{w}+\left(k e^{\gamma(w-z)}+\lambda\right)^{\frac{1-\alpha}{\alpha}} C \\
& =A(w)+\frac{\delta U}{k}-\frac{\delta U}{k}(k+\lambda)^{\frac{-(1-\alpha)}{\alpha}}\left(k e^{\gamma(w-z)}+\lambda\right)^{\frac{1-\alpha}{\alpha}}+\left(k e^{\gamma(w-z)}+\lambda\right)^{\frac{1-\alpha}{\alpha}} C \\
& =A(w)+\frac{\delta}{k} C(k+\lambda)^{\frac{1-\alpha}{\alpha}}+\frac{r}{k} C\left(k e^{\gamma(w-z)}+\lambda\right)^{\frac{1-\alpha}{\alpha}}
\end{aligned}
$$

where in the last equation we use that $U=(k+\lambda)^{\frac{1-\alpha}{\alpha}} C$. Differentiating $W(w)$ with respect to $w$ we get:

$$
W^{\prime}(w)=A^{\prime}(w)+r C \gamma e^{\gamma(w-z)} \frac{(1-\alpha)}{\alpha}\left(k e^{\gamma(w-z)}+\lambda\right)^{\frac{1-\alpha}{\alpha}-1}
$$

Inserting (12) into (4) we get:

$$
\begin{aligned}
k W(w) & =w+\lambda \int_{w}^{\infty} e^{-\gamma \frac{(t-(1-\alpha) w-\alpha z)}{\alpha}}\left[A^{\prime}(t)+r C \gamma e^{\gamma(t-z)} \frac{(1-\alpha)}{\alpha}\left(k e^{\gamma(t-z)}+\lambda\right)^{\frac{1-\alpha}{\alpha}-1}\right] d t+\delta U \\
& =w+\delta U+\lambda \int_{w}^{\infty} e^{-\gamma \frac{(t-(1-\alpha) w-\alpha z)}{\alpha}} A^{\prime}(t) d t-\left.r C e^{\gamma \frac{(1-\alpha)(w-z)}{\alpha}}\left(\left(k+\lambda e^{-\gamma(t-z)}\right)^{\frac{1-\alpha}{\alpha}}\right)\right|_{w} ^{\infty} \\
& =w+\delta U+\lambda \int_{w}^{\infty} e^{-\gamma \frac{(t-(1-\alpha) w-\alpha z)}{\alpha}} A^{\prime}(t) d t-r C e^{\gamma \frac{(1-\alpha)(w-z)}{\alpha}}\left(k^{\frac{1-\alpha}{\alpha}}-\left(k+\lambda e^{-\gamma(w-z)}\right)^{\frac{1-\alpha}{\alpha}}\right)
\end{aligned}
$$

Evaluating this equation at $w=z$ and using that $U=(k+\lambda)^{\frac{1-\alpha}{\alpha}} C$ we get the following equation for $C$ :

$$
k W(z)=z+\delta C(k+\lambda)^{\frac{(1-\alpha)}{\alpha}}+\lambda \int_{z}^{\infty} e^{-\gamma \frac{(t-z)}{\alpha}} A^{\prime}(t) d t-r C\left(k^{\frac{1-\alpha}{\alpha}}-(k+\lambda)^{\frac{1-\alpha}{\alpha}}\right)=k C(k+\lambda)^{\frac{(1-\alpha)}{\alpha}}
$$

So the integration constant $C$ is given by:

$$
r k^{\frac{1-\alpha}{\alpha}} C=z+\lambda \int_{z}^{\infty} e^{-\gamma \frac{(t-z)}{\alpha}} A^{\prime}(t) d t
$$

\section{Appendix II:}

Proof of proposition 2, part a. If $\alpha=0.5$ and $z=0$ auxiliary function $A(w)$ can be written as:

$$
\begin{aligned}
A(w) & =\left(k e^{\gamma w}+\lambda\right) \int_{0}^{w} \frac{(1-\gamma x)\left(k e^{\gamma x}+\lambda\right)^{-1}}{\left(k+\lambda e^{-\gamma x}\right)} d x=\left(k e^{\gamma w}+\lambda\right) \int_{0}^{w} \frac{(1-\gamma x) e^{\gamma x}}{\left(k e^{\gamma x}+\lambda\right)^{2}} d x \\
& =\left.\left(k e^{\gamma w}+\lambda\right)\left[-\frac{1}{\gamma k\left(k e^{\gamma x}+\lambda\right)}+\frac{\ln \left(k e^{\gamma x}+\lambda\right)}{\gamma \lambda k}-\frac{x e^{\gamma x}}{\lambda\left(k e^{\gamma x}+\lambda\right)}\right]\right|_{0} ^{w} \\
& =\left(k e^{\gamma w}+\lambda\right)\left[-\frac{1}{\gamma k\left(k e^{\gamma w}+\lambda\right)}+\frac{\ln \left(k e^{\gamma w}+\lambda\right)}{\gamma \lambda k}-\frac{w e^{\gamma w}}{\lambda\left(k e^{\gamma w}+\lambda\right)}+\frac{1}{\gamma k(k+\lambda)}-\frac{\ln (k+\lambda)}{\gamma \lambda k}\right] \\
& =\left(k e^{\gamma w}+\lambda\right)\left[\frac{e^{\gamma w}-1}{\gamma(k+\lambda)\left(k e^{\gamma w}+\lambda\right)}+\frac{\ln \left(k e^{\gamma w}+\lambda\right)-\ln (k+\lambda)}{\gamma \lambda k}-\frac{w e^{\gamma w}}{\lambda\left(k e^{\gamma w}+\lambda\right)}\right] \\
& =\frac{e^{\gamma w}-1}{\gamma(k+\lambda)}+\left(k e^{\gamma w}+\lambda\right) \frac{\left[\ln \left(k e^{\gamma w}+\lambda\right)-\ln (k+\lambda)\right]}{\gamma \lambda k}-\frac{w e^{\gamma w}}{\lambda}
\end{aligned}
$$




$$
\begin{aligned}
A^{\prime}(w)=\frac{e^{\gamma w}}{k+\lambda}+\frac{e^{\gamma w}}{\lambda}\left[\ln \left(k e^{\gamma w}+\lambda\right)-\ln (k+\lambda)\right]-\frac{w \gamma e^{\gamma w}}{\lambda} \\
r k C=\lambda \int_{0}^{\infty} e^{-2 \gamma w} A^{\prime}(w) d w=\lambda \int_{0}^{\infty}\left[\frac{e^{-\gamma w}}{k+\lambda}+\frac{e^{-\gamma w}}{\lambda}\left[\ln \left(k e^{\gamma w}+\lambda\right)-\ln (k+\lambda)\right]-\frac{w \gamma e^{-\gamma w}}{\lambda}\right] d w \\
=\left.\lambda\left(-\frac{e^{-\gamma w}}{\gamma(k+\lambda)}+\frac{e^{-\gamma w} \ln (k+\lambda)}{\gamma \lambda}-\frac{e^{-\gamma w} \ln \left(k+\lambda e^{-\gamma w}\right)}{\gamma \lambda}-\frac{k \ln \left(k+\lambda e^{-\gamma w}\right)}{\gamma \lambda^{2}}+\frac{e^{-\gamma w}}{\gamma \lambda}\right)\right|_{0} ^{\infty} \\
=\lambda\left(-\frac{k \ln (k)}{\gamma \lambda^{2}}+\frac{1}{\gamma(k+\lambda)}-\frac{\ln (k+\lambda)}{\gamma \lambda}+\frac{\ln (k+\lambda)}{\gamma \lambda}+\frac{k \ln (k+\lambda)}{\gamma \lambda^{2}}-\frac{1}{\gamma \lambda}\right) \\
=-\frac{k \ln (k)}{\gamma \lambda}+\frac{\lambda}{\gamma(k+\lambda)}+\frac{k \ln (k+\lambda)}{\gamma \lambda}-\frac{1}{\gamma}=\frac{k(\ln (k+\lambda)-\ln (k))}{\gamma \lambda}-\frac{k}{\gamma(k+\lambda)} \\
=\frac{1}{\gamma}\left[\frac{(\ln (k+\lambda)-\ln (k))}{\lambda}-\frac{1}{(k+\lambda)}\right] \\
=\frac{e^{\gamma w}-1}{\gamma(k+\lambda)}+\left(k e^{\gamma w}+\lambda\right) \frac{\left.\ln \left(k e^{\gamma w}+\lambda\right)-\ln (k+\lambda)\right]}{\gamma \lambda k}-\frac{w e^{\gamma w}}{\lambda}+\frac{\delta}{k} C(k+\lambda)+\frac{r}{k} C\left(k e^{\gamma w}+\lambda\right)
\end{aligned}
$$

Insert $C$ into the last term to obtain:

$$
\begin{aligned}
& W(w)= \frac{e^{\gamma w}-1}{\gamma(k+\lambda)}+\left(k e^{\gamma w}+\lambda\right) \frac{\left[\ln \left(k e^{\gamma w}+\lambda\right)-\ln (k+\lambda)\right]}{\gamma \lambda k}-\frac{w e^{\gamma w}}{\lambda}+\frac{\delta}{k} C(k+\lambda) \\
&+ \frac{\left(k e^{\gamma w}+\lambda\right)}{k \gamma}\left[\frac{(\ln (k+\lambda)-\ln (k))}{\lambda}-\frac{1}{(k+\lambda)}\right]=\frac{e^{\gamma w}-1}{\gamma(k+\lambda)}+\left(k e^{\gamma w}+\lambda\right) \frac{\ln \left(k e^{\gamma w}+\lambda\right)}{\gamma \lambda k} \\
&- \frac{w e^{\gamma w}}{\lambda}+\frac{\delta}{k} C(k+\lambda)-\frac{\left(k e^{\gamma w}+\lambda\right) \ln (k)}{k \gamma \lambda}-\frac{\left(k e^{\gamma w}+\lambda\right)}{k \gamma(k+\lambda)} \\
&= \frac{-1}{\gamma(k+\lambda)}+\left(k e^{\gamma w}+\lambda\right) \frac{\ln \left(k e^{\gamma w}+\lambda\right)}{\gamma \lambda k}-\frac{w e^{\gamma w}}{\lambda}+\frac{\delta}{k} C(k+\lambda)-\frac{\left(k e^{\gamma w}+\lambda\right) \ln (k)}{k \gamma \lambda}-\frac{\lambda}{k \gamma(k+\lambda)} \\
&=-\frac{1}{k \gamma}(1+\ln k)+\frac{\delta}{k}(k+\lambda) C+\frac{\left(k e^{\gamma w}+\lambda\right)}{\gamma \lambda k} \ln \left(k e^{\gamma w}+\lambda\right)-\frac{w e^{\gamma w}}{\lambda}-\frac{e^{\gamma w} \ln (k)}{\gamma \lambda} \\
& k W(w)=w+\delta(k+\lambda) C+\frac{\left(k e^{\gamma w}+\lambda\right)\left[\ln \left(k+\lambda e^{-\gamma w}\right)-\ln k\right]}{\gamma \lambda}-\frac{1}{\gamma} \\
& k W^{\prime}(w)=\frac{k}{\lambda} e^{\gamma w}\left[\ln \left(k+\lambda e^{-\gamma w}\right)-\ln (k)\right]=\frac{k}{\lambda} e^{\gamma w} \ln \left(1+\frac{\lambda}{k} e^{-\gamma w}\right)>0
\end{aligned}
$$

The second order derivative of $W(w)$ with respect to $w$ becomes:

$$
\begin{aligned}
W^{\prime \prime}(w) & =\frac{1}{\lambda}\left[e^{\gamma w} \gamma \ln \left(1+\frac{\lambda}{k} e^{-\gamma w}\right)+e^{\gamma w} \frac{1}{\left(1+\frac{\lambda}{k} e^{-\gamma w}\right)} \frac{\lambda}{k} e^{-\gamma w}(-\gamma)\right] \\
& =\frac{\gamma}{\lambda}\left[e^{\gamma w} \ln \left(1+\frac{\lambda}{k} e^{-\gamma w}\right)-\frac{\lambda}{k} \frac{1}{\left(1+\frac{\lambda}{k} e^{-\gamma w}\right)}\right]>0
\end{aligned}
$$

To obtain the result that $W^{\prime \prime}(w)>0$ denote the term $k e^{\gamma w} / \lambda=\omega>0$, so $k W^{\prime \prime}(\omega)$ becomes:

$$
W^{\prime \prime}(\omega)=\frac{\gamma}{k} \omega\left[\ln \left(1+\frac{1}{\omega}\right)-\frac{1}{\omega\left(1+\frac{1}{\omega}\right)}\right]=\frac{\gamma \omega}{k} \frac{\left[(\omega+1) \ln \left(1+\frac{1}{\omega}\right)-1\right]}{(\omega+1)}>0
$$

As shown in the proof of proposition 2 , part b, the function $(\omega+1) \ln \left(1+\frac{1}{\omega}\right)$ is monotonically decreasing in $\omega$ and converging to 1 from above, so that $(\omega+1) \ln \left(1+\frac{1}{\omega}\right)>1$. Thus $W^{\prime \prime}(w)>0$. 
Proof of proposition 2, part b. If $\alpha=1 / 3$ and $z=0$ function $A(w)$ can be written as:

$$
\begin{aligned}
& A(w)=\left(k e^{\gamma w}+\lambda\right)^{2} \int_{0}^{w} \frac{(1-2 \gamma x)\left(k e^{\gamma x}+\lambda\right)^{-2}}{\left(k+\lambda e^{-\gamma x}\right)} d x=\left(k e^{\gamma w}+\lambda\right)^{2} \int_{0}^{w} \frac{(1-2 \gamma x) e^{\gamma x}}{\left(k e^{\gamma x}+\lambda\right)^{3}} d x \\
& =\frac{w}{k}+\frac{\left(k e^{\gamma w}+\lambda\right)^{2} \ln \left(k+\lambda e^{-\gamma w}\right)}{\gamma \lambda^{2} k}-\frac{\left(k e^{\gamma w}+\lambda\right)}{\gamma \lambda k}-\frac{1}{2 \gamma k} \\
& -\left(k e^{\gamma w}+\lambda\right)^{2}\left[\frac{\ln (k+\lambda)}{\gamma \lambda^{2} k}-\frac{1}{\gamma \lambda k(k+\lambda)}-\frac{1}{2 \gamma k(k+\lambda)^{2}}\right] \\
& A^{\prime}(w)=\frac{1}{k}+\frac{2\left(k e^{\gamma w}+\lambda\right) e^{\gamma w} \ln \left(k+\lambda e^{-\gamma w}\right)}{\lambda^{2}}-\frac{\left(k e^{\gamma w}+\lambda\right)^{2} e^{-\gamma w}}{\left(k+\lambda e^{-\gamma w}\right) \lambda k}-\frac{e^{\gamma w}}{\lambda} \\
& -2 k \gamma e^{\gamma w}\left(k e^{\gamma w}+\lambda\right)\left[\frac{\ln (k+\lambda)}{\gamma \lambda^{2} k}-\frac{1}{\gamma \lambda k(k+\lambda)}-\frac{1}{2 \gamma k(k+\lambda)^{2}}\right] \\
& =\frac{2\left(k e^{\gamma w}+\lambda\right) e^{\gamma w}\left[\ln \left(k+\lambda e^{-\gamma w}\right)-\ln (k+\lambda)\right]}{\lambda^{2}}-\frac{2 e^{\gamma w}}{\lambda} \\
& +2 e^{\gamma w}\left(k e^{\gamma w}+\lambda\right)\left[\frac{1}{\lambda(k+\lambda)}+\frac{1}{2(k+\lambda)^{2}}\right] \\
& r k^{2} C=\lambda \int_{0}^{\infty} e^{-3 \gamma w} A^{\prime}(w) d w=\frac{k^{2}}{\gamma \lambda}\left[\frac{\ln (k+\lambda)-\ln k}{\lambda}-\frac{1}{k+\lambda}-\frac{\lambda}{2(k+\lambda)^{2}}\right] \\
& W(w)=A(w)+\frac{\delta}{k} C(k+\lambda)^{2}+\frac{r}{k} C\left(k e^{\gamma w}+\lambda\right)^{2} \\
& =\frac{w}{k}+\frac{\left(k e^{\gamma w}+\lambda\right)^{2} \ln \left(k+\lambda e^{-\gamma w}\right)}{\gamma \lambda^{2} k}-\frac{\left(k e^{\gamma w}+\lambda\right)}{\gamma \lambda k}-\frac{1}{2 \gamma k} \\
& -\left(k e^{\gamma w}+\lambda\right)^{2}\left[\frac{\ln (k+\lambda)}{\gamma \lambda^{2} k}-\frac{1}{\gamma \lambda k(k+\lambda)}-\frac{1}{2 \gamma k(k+\lambda)^{2}}\right]+\frac{\delta}{k} C(k+\lambda)^{2} \\
& +\frac{r}{r k \gamma \lambda}\left(k e^{\gamma w}+\lambda\right)^{2}\left[\frac{\ln (k+\lambda)-\ln k}{\lambda}-\frac{1}{k+\lambda}-\frac{\lambda}{2(k+\lambda)^{2}}\right] \\
& =\frac{w}{k}+\frac{\left(k e^{\gamma w}+\lambda\right)^{2}\left[\ln \left(k+\lambda e^{-\gamma w}\right)-\ln k\right]}{\gamma \lambda^{2} k}-\frac{\left(k e^{\gamma w}+\lambda\right)}{\gamma \lambda k}-\frac{1}{2 \gamma k}+\frac{\delta}{k} C(k+\lambda)^{2} \\
& \begin{aligned}
k W^{\prime}(w) & =1+\frac{2 k e^{\gamma w}}{\lambda^{2}}\left(k e^{\gamma w}+\lambda\right)\left[\ln \left(k+\lambda e^{-\gamma w}\right)-\ln k\right]-\frac{\left(k e^{\gamma w}+\lambda\right)^{2}}{\lambda\left(k e^{\gamma w}+\lambda\right)}-\frac{k e^{\gamma w}}{\lambda} \\
& =\frac{2 k e^{\gamma w}}{\lambda^{2}}\left(k e^{\gamma w}+\lambda\right)\left[\ln \left(k+\lambda e^{-\gamma w}\right)-\ln k\right]-\frac{2 k e^{\gamma w}}{\lambda}=\frac{2 k e^{\gamma w}}{\lambda}\left[\left(\frac{k}{\lambda} e^{\gamma w}+1\right) \ln \left(1+\frac{\lambda}{k} e^{-\gamma w}\right)-1\right]>0
\end{aligned}
\end{aligned}
$$

To obtain the result that $W^{\prime}(w)>0$ denote the term $k e^{\gamma w} / \lambda=\omega>0$, so $k W^{\prime}(\omega)$ becomes:

$$
k W^{\prime}(\omega)=2 \omega\left[(\omega+1) \ln \left(1+\frac{1}{\omega}\right)-1\right]
$$

Differentiate the term $(\omega+1) \ln \left(1+\frac{1}{\omega}\right)$ with respect to $\omega$ :

$$
\ln \left(1+\frac{1}{\omega}\right)-\frac{(\omega+1) \omega}{\omega^{2}(\omega+1)}=\ln \left(1+\frac{1}{\omega}\right)-\frac{1}{\omega}<0
$$

This means that $(\omega+1) \ln \left(1+\frac{1}{\omega}\right)$ is monotonically decreasing in $\omega$. Next consider the limit for $\omega \rightarrow \infty$ :

$$
\lim _{\omega \rightarrow \infty}(\omega+1) \ln \left(1+\frac{1}{\omega}\right)=\lim _{\omega \rightarrow \infty} \frac{\ln \left(1+\frac{1}{\omega}\right)}{\frac{1}{1+\omega}}=\lim _{\omega \rightarrow \infty} \frac{\omega(1+\omega)^{2}}{\omega^{2}(1+\omega)}=\lim _{\omega \rightarrow \infty} \frac{1+\omega}{\omega}=1
$$


This shows that function $(\omega+1) \ln \left(1+\frac{1}{\omega}\right)$ is monotonically decreasing in $\omega$ and converging to 1 from above, so that $(\omega+1) \ln \left(1+\frac{1}{\omega}\right)>1$ and $W^{\prime}(w)>0$.

The second order derivative of $W(w)$ with respect to $w$ becomes:

$$
\begin{aligned}
k W^{\prime \prime}(w) & =\frac{2 k e^{\gamma w}}{\lambda} \gamma\left[\left(\frac{k}{\lambda} e^{\gamma w}+1\right) \ln \left(1+\frac{\lambda}{k} e^{-\gamma w}\right)-1\right] \\
& +\frac{2 k e^{\gamma w}}{\lambda}\left[\frac{k e^{\gamma w} \gamma}{\lambda} \ln \left(1+\frac{\lambda}{k} e^{-\gamma w}\right)+\left(\frac{k}{\lambda} e^{\gamma w}+1\right) \frac{1}{\left(1+\frac{\lambda}{k} e^{-\gamma w}\right)} \frac{\lambda}{k} e^{-\gamma w}(-\gamma)\right]
\end{aligned}
$$

Using the same notation the term $k e^{\gamma w} / \lambda=\omega>0$, so $k W^{\prime \prime}(\omega)$ becomes:

$$
k W^{\prime \prime}(\omega)=2 \omega \gamma\left[(1+\omega) \ln \left(1+\frac{1}{\omega}\right)-1\right]+2 \omega \gamma\left[\omega \ln \left(1+\frac{1}{\omega}\right)-1\right]=2 \omega \gamma\left[(1+2 \omega) \ln \left(1+\frac{1}{\omega}\right)-2\right]
$$

Differentiate the term $(1+2 \omega) \ln \left(1+\frac{1}{\omega}\right)$ with respect to $\omega$ :

$$
2 \ln \left(1+\frac{1}{\omega}\right)+(1+2 \omega) \frac{1}{\left(1+\frac{1}{\omega}\right)}\left(-\frac{1}{\omega^{2}}\right)=2 \ln \left(1+\frac{1}{\omega}\right)-\frac{(1+2 \omega)}{\left(\omega^{2}+\omega\right)}<0
$$

To prove this inequality differentiate the term $2 \ln \left(1+\frac{1}{\omega}\right)-\frac{(1+2 \omega)}{\left(\omega^{2}+\omega\right)}$ with respect to $\omega$ :

$$
\frac{2}{\left(1+\frac{1}{\omega}\right)}\left(-\frac{1}{\omega^{2}}\right)-\left[\frac{\left.2\left(\omega^{2}+\omega\right)-(1+2 \omega)(2 \omega+1)\right)}{\left(\omega^{2}+\omega\right)^{2}}\right]=-\frac{2}{\left(\omega^{2}+\omega\right)}+\frac{2 \omega^{2}+2 \omega+1}{\left(\omega^{2}+\omega\right)^{2}}=\frac{1}{\left(\omega^{2}+\omega\right)^{2}}>0
$$

This means the term $2 \ln \left(1+\frac{1}{\omega}\right)-\frac{(1+2 \omega)}{\left(\omega^{2}+\omega\right)}$ is monotonically increasing in $\omega$. It is clear that $\lim _{\omega \rightarrow \infty} 2 \ln (1+$ $\left.\frac{1}{\omega}\right)-\frac{(1+2 \omega)}{\left(\omega^{2}+\omega\right)}=0$. Thus the term $(1+2 \omega) \ln \left(1+\frac{1}{\omega}\right)$ is monotonically decreasing in $\omega$. Next consider the limit for $\omega \rightarrow \infty$ :

$$
\lim _{\omega \rightarrow \infty}(1+2 \omega) \ln \left(1+\frac{1}{\omega}\right)=\lim _{\omega \rightarrow \infty} \frac{\ln \left(1+\frac{1}{\omega}\right)}{\frac{1}{1+2 \omega}}=\lim _{\omega \rightarrow \infty} \frac{\frac{1}{\omega^{2}+\omega}}{\frac{2}{(2 \omega+1)^{2}}}=\lim _{\omega \rightarrow \infty} \frac{(2 \omega+1)^{2}}{2\left(\omega^{2}+\omega\right)}=2
$$

This shows that function $2 \ln \left(1+\frac{1}{\omega}\right)-\frac{(1+2 \omega)}{\left(\omega^{2}+\omega\right)}$ is monotonically decreasing in $\omega$ and converging to 2 from above, so that $2 \ln \left(1+\frac{1}{\omega}\right)-\frac{(1+2 \omega)}{\left(\omega^{2}+\omega\right)}>2$ and $W^{\prime \prime}(w)>0$.

Proof of proposition 2, part c. If $\alpha=1 / 4$ we get the following differential equation:

$$
W^{\prime}(w)=\frac{1-3 \gamma(w+\delta U)}{k+\lambda e^{-\gamma w}}+\frac{3 \gamma k}{k+\lambda e^{-\gamma w}} W(w)
$$

The general solution of this equation is given by:

$$
\begin{aligned}
k W(w) & =\delta U-\frac{\left(k e^{\gamma w}+\lambda\right)^{2}}{\gamma \lambda^{2}}-\frac{k e^{\gamma w}+\lambda}{2 \gamma \lambda}+\frac{\left(k e^{\gamma w}+\lambda\right)^{3}\left[\gamma w+\ln \left(k+\lambda e^{-\gamma w}\right)-\ln (k)\right]}{\gamma \lambda^{3}} \\
& -\frac{w e^{3 \gamma w} k^{3}}{\lambda^{3}}-\frac{3 w e^{2 \gamma w} k^{2}}{\lambda^{2}}-\frac{3 w e^{\gamma w} k}{\lambda}-\frac{1}{3 \gamma}
\end{aligned}
$$

Using that $W(0)=U$, we find the present value of unemployment $U$ from the above equation:

$$
\frac{r U}{(k+\lambda)^{3}}=r C=\frac{1}{\gamma \lambda^{2}}\left[\frac{[\ln (k+\lambda)-\ln (k)]}{\lambda}-\frac{1}{k+\lambda}-\frac{\lambda}{2(k+\lambda)^{2}}-\frac{\lambda^{2}}{3(k+\lambda)^{3}}\right]
$$

In order to find a value function note that:

$$
\frac{\left(k e^{\gamma w}+\lambda\right)^{3} w}{\lambda^{3}}=\frac{w e^{3 \gamma w} k^{3}}{\lambda^{3}}+\frac{3 w e^{2 \gamma w} k^{2}}{\lambda^{2}}+\frac{w 3 e^{\gamma w} k}{\lambda}+w
$$


The first three terms cancel out in equation (13), so the value function $W(w)$ can be written as:

$$
k W(w)=w+\delta U+\frac{\left(k e^{\gamma w}+\lambda\right)^{3}\left[\ln \left(k+\lambda e^{-\gamma w}\right)-\ln (k)\right]}{\gamma \lambda^{3}}-\frac{\left(k e^{\gamma w}+\lambda\right)^{2}}{\gamma \lambda^{2}}-\frac{k e^{\gamma w}+\lambda}{2 \gamma \lambda}-\frac{1}{3 \gamma}
$$

Next we differentiate $W(w)$ with respect to $w$ :

$$
\begin{aligned}
k W^{\prime}(w) & =1+\frac{3\left(k e^{\gamma w}+\lambda\right)^{2}\left[\ln \left(k+\lambda e^{-\gamma w}\right)-\ln (k)\right] k e^{\gamma w}}{\lambda^{3}}-\frac{\left(k e^{\gamma w}+\lambda\right)^{3}}{\left(k e^{\gamma w}+\lambda\right) \lambda^{2}}-\frac{2\left(k e^{\gamma w}+\lambda\right) k e^{\gamma w}}{\lambda^{2}}-\frac{k e^{\gamma w}}{2 \lambda} \\
& =1+\frac{3\left(\frac{k}{\lambda} e^{\gamma w}+1\right)^{2}\left[\ln \left(1+\frac{\lambda}{k} e^{-\gamma w}\right)\right] k e^{\gamma w}}{\lambda}-\frac{\left(k^{2} e^{2 \gamma w}+2 k e^{\gamma w} \lambda+\lambda^{2}\right)}{\lambda^{2}}-\frac{2 k^{2} e^{2 \gamma w}+2 \lambda k e^{\gamma w}}{\lambda^{2}}-\frac{k e^{\gamma w}}{2 \lambda} \\
& =3(\omega+1)^{2}\left[\ln \left(1+\frac{1}{\omega}\right)\right] \omega-\frac{9}{2} \omega-3 \omega^{2}=3 \omega\left((\omega+1)^{2}\left[\ln \left(1+\frac{1}{\omega}\right)\right]-\omega-1.5\right)
\end{aligned}
$$

where $\omega=\frac{k}{\lambda} e^{\gamma w}$ as before. Next we determine the sign of function $\Omega(w)=(\omega+1)^{2}\left[\ln \left(1+\frac{1}{\omega}\right)\right]-\omega$

$$
\begin{aligned}
\Omega^{\prime}(w) & =2(\omega+1) \ln \left(1+\frac{1}{\omega}\right)-2-\frac{1}{\omega} \text { with } \lim _{w \rightarrow \infty} \Omega^{\prime}(w)=0 \\
\Omega^{\prime \prime}(w) & =2 \ln \left(1+\frac{1}{\omega}\right)-\frac{2}{\omega}+\frac{1}{\omega^{2}} \text { with } \lim _{w \rightarrow \infty} \Omega^{\prime \prime}(w)=0 \\
\Omega^{\prime \prime \prime}(w) & =-\frac{2}{(\omega+1) \omega}+\frac{2}{\omega^{2}}-\frac{2}{\omega^{3}}=-\frac{2}{(\omega+1) \omega^{3}}<0
\end{aligned}
$$

This means that $\Omega^{\prime \prime}(\omega)$ is a monotonically decreasing function converging to 0 from above, which implies that $\Omega^{\prime \prime}(\omega)>0 \forall \omega>0$. At the same time this means that $\Omega^{\prime}(\omega)$ is a monotonically increasing function converging to 0 from below, so that $\Omega^{\prime}(\omega)<0 \forall \omega>0$. This proves that $\Omega(\omega)$ is a decreasing function. Moreover, defining $t=1 / \omega$ one can show that:

$$
\begin{aligned}
\lim _{\omega \rightarrow \infty} \Omega(\omega) & =\lim _{\omega \rightarrow \infty}(\omega+1)^{2}\left[\ln \left(1+\frac{1}{\omega}\right)\right]-\omega=\lim _{t \rightarrow 0}\left(\frac{1}{t}+1\right)^{2}[\ln (1+t)]-\frac{1}{t}=\lim _{t \rightarrow 0} \frac{(1+t)^{2}[\ln (1+t)]-t}{t^{2}} \\
& =\lim _{t \rightarrow 0} \frac{2(1+t)[\ln (1+t)]+t+1-1}{2 t}=\lim _{t \rightarrow 0} \frac{2[\ln (1+t)]+2+1}{2}=1.5
\end{aligned}
$$

where in the second line we used the L'Hopital rule. This proves that $\Omega(\omega)-1.5>0$, so that $W^{\prime}(w)>0$.

Next let's consider the second order derivative of $W(w)$ with respect to $w$ :

$$
\begin{aligned}
k W^{\prime \prime}(w) & =3 \frac{\partial \omega}{\partial w}\left((\omega+1)^{2}\left[\ln \left(1+\frac{1}{\omega}\right)\right]-\omega-1.5+\omega 2(\omega+1)\left[\ln \left(1+\frac{1}{\omega}\right)\right]-(\omega+1)-\omega\right) \\
& =3 \gamma \omega\left(\left(3 \omega^{2}+4 \omega+1\right)\left[\ln \left(1+\frac{1}{\omega}\right)\right]-3 \omega-2.5\right)=3 \gamma \omega\left((\omega+1)(3 \omega+1)\left[\ln \left(1+\frac{1}{\omega}\right)\right]-3 \omega-2.5\right)
\end{aligned}
$$

where $\omega=\frac{k}{\lambda} e^{\gamma w}$ as before. Next we define the function $\Phi(\omega)=(\omega+1)(3 \omega+1) \ln \left(1+\frac{1}{\omega}\right)-3 \omega$ and prove that $\Phi(\omega)>2.5 \forall \omega>0$.

$$
\begin{aligned}
\Phi^{\prime}(w)= & (6 \omega+4) \ln \left(1+\frac{1}{\omega}\right)-6-\frac{1}{\omega} \text { with } \lim _{w \rightarrow \infty} \Phi^{\prime}(w)=0 \\
\Phi^{\prime \prime}(w)= & 6 \ln \left(1+\frac{1}{\omega}\right)-\frac{6 \omega+4}{\omega(\omega+1)}+\frac{1}{\omega^{2}}=6 \ln \left(1+\frac{1}{\omega}\right)-\frac{6 \omega^{2}+3 \omega-1}{\omega^{2}(\omega+1)} \text { with } \lim _{w \rightarrow \infty} \Phi^{\prime \prime}(w)=0 \\
\Phi^{\prime \prime \prime}(w) & =\frac{6}{\left(1+\frac{1}{\omega}\right)}\left(-\frac{1}{\omega^{2}}\right)-\frac{\omega\left[(12 \omega+3) \omega(\omega+1)-\left(6 \omega^{2}+3 \omega-1\right)(3 \omega+2)\right]}{\omega^{4}(\omega+1)^{2}}= \\
& =-\frac{6}{\omega(\omega+1)}-\frac{\left[12 \omega^{3}+12 \omega^{2}+3 \omega^{2}+3 \omega-18 \omega^{3}-12 \omega^{2}-9 \omega^{2}-6 \omega+3 \omega+2\right]}{\omega^{3}(\omega+1)^{2}}= \\
& =-\frac{6}{\omega(\omega+1)}-\frac{\left[-6 \omega^{3}-6 \omega^{2}+2\right]}{\omega^{3}(\omega+1)^{2}}=-\frac{2}{\omega^{3}(\omega+1)^{2}}<0
\end{aligned}
$$


This means that $\Phi^{\prime \prime}(\omega)$ is a monotonically decreasing function converging to 0 from above, which implies that $\Phi^{\prime \prime}(\omega)>0 \forall \omega>0$. At the same time this means that $\Phi^{\prime}(\omega)$ is a monotonically increasing function converging to 0 from below, so that $\Phi^{\prime}(\omega)<0 \forall \omega>0$. This proves that $\Phi(\omega)$ is a decreasing function. Moreover, one can show that:

$$
\begin{aligned}
\lim _{\omega \rightarrow \infty} \Phi(\omega) & =\lim _{\omega \rightarrow \infty}(\omega+1)(3 \omega+1) \ln \left(1+\frac{1}{\omega}\right)-3 \omega=\lim _{t \rightarrow 0}\left(\frac{1}{t}+1\right)\left(\frac{3}{t}+1\right)[\ln (1+t)]-\frac{3}{t}= \\
& =\lim _{t \rightarrow 0} \frac{\left(t^{2}+4 t+3\right)[\ln (1+t)]-3 t}{t^{2}}=\lim _{t \rightarrow 0} \frac{2(t+2)[\ln (1+t)]+t+1+2-3}{2 t} \\
& =\lim _{t \rightarrow 0} \frac{2[\ln (1+t)]+2+\frac{2}{1+t}+1}{2}=2.5
\end{aligned}
$$

which proves that $\Phi(\omega)-2.5>0$, so that $W^{\prime \prime}(w)>0 \forall w>0$.

If $\alpha=1$ and $z=0$ auxiliary function $A(w)$ can be written as:

$$
\begin{gathered}
A(w)=\int_{0}^{w} \frac{d x}{\left(k+\lambda e^{-\gamma x}\right)} \quad A^{\prime}(w)=\frac{1}{\left(k+\lambda e^{-\gamma w}\right)} \\
r C=\quad \lambda \int_{0}^{\infty} \frac{e^{-\gamma w}}{\left(k+\lambda e^{-\gamma w}\right)} d w=-\frac{1}{\gamma} \int_{0}^{\infty} \frac{d \lambda e^{-\gamma w}}{\left(k+\lambda e^{-\gamma w}\right)} \\
=\quad-\left.\frac{1}{\gamma} \ln \left(k+\lambda e^{-\gamma w}\right)\right|_{w=0} ^{\infty}=-\frac{1}{\gamma}(\ln k-\ln (k+\lambda))=\frac{1}{\gamma}(\ln (k+\lambda)-\ln k) \\
W(w)=\int_{0}^{w} \frac{1}{\left(k+\lambda e^{-\gamma x}\right)} d x+C=\int_{0}^{w} \frac{e^{\gamma x}}{\left(k e^{\gamma x}+\gamma\right)} d x+C \\
=\frac{1}{k \gamma} \int_{0}^{w} \frac{d k e^{\gamma x}}{\left(k e^{\gamma x}+\lambda\right)}+C=\left.\frac{1}{k \gamma} \ln \left(k e^{\gamma x}+\lambda\right)\right|_{0} ^{w}+C \\
\frac{\ln \left(k e^{\gamma w}+\lambda\right)-\ln (k+\lambda)}{k \gamma}+C=\frac{\ln \left(k e^{\gamma w}+\lambda\right)}{k \gamma}-\frac{\ln (k+\lambda)}{k \gamma}+C
\end{gathered}
$$

Taking derivative of $W(w)$ with respect to $w$ we can obtain:

$$
W^{\prime}(w)=\frac{e^{\gamma w}}{\left(k e^{\gamma w}+\lambda\right)}>0 \quad W^{\prime \prime}(w)=\frac{\gamma e^{\gamma w}\left(k e^{\gamma w}+\lambda\right)-k \gamma e^{2 \gamma w}}{\left(k e^{\gamma w}+\lambda\right)^{2}}=\frac{\gamma \lambda e^{\gamma w}}{\left(k e^{\gamma w}+\lambda\right)^{2}}>0
$$

Hence the present value of being employed is an increasing and convex function of $w$. Note that the value function $W(w)$ can be rewritten in the spirit of proposition $2($ since $k-r=\delta)$ :

$$
\begin{aligned}
k W(w) & =\frac{\ln \left(k e^{\gamma w}+\lambda\right)}{\gamma}-\frac{\ln (k+\lambda)}{\gamma}+\frac{k}{r \gamma}(\ln (k+\lambda)-\ln k) \\
& =w+\frac{\left[\ln \left(k+\lambda e^{-\gamma w}\right)-\ln k\right]}{\gamma}-\frac{r[\ln (k+\lambda)-\ln k]}{r \gamma}+\frac{k}{r \gamma}(\ln (k+\lambda)-\ln k) \\
& =w+\frac{\left[\ln \left(k+\lambda e^{-\gamma w}\right)-\ln k\right]}{\gamma}+\delta C \quad \text { where } \quad r C=\frac{1}{\gamma}(\ln (k+\lambda)-\ln k)
\end{aligned}
$$

Appendix III: proof of lemma 2.

$$
\begin{aligned}
J^{\prime \prime}(y, w) & =\frac{\left.\left[(-1) \lambda(-\gamma) e^{-\gamma(w-z)}\right)+(-1) \lambda \gamma e^{-\gamma(w-z)}+(y-w) \lambda \gamma e^{-\gamma(w-z)}(-\gamma)\right]\left(k+\lambda e^{-\gamma(w-z)}\right)^{2}}{\left(k+\lambda e^{-\gamma(w-z)}\right)^{4}} \\
& -\frac{\left[(-1)\left(k+\lambda e^{-\gamma(w-z)}\right)+(y-w) \lambda \gamma e^{-\gamma(w-z)}\right] 2\left(k+\lambda e^{-\gamma(w-z)}\right) \lambda(-\gamma) e^{-\gamma(w-z)}}{\left(k+\lambda e^{-\gamma(w-z)}\right)^{4}} \\
& =-\frac{(y-w) \lambda \gamma^{2} e^{-\gamma(w-z)}}{\left(k+\lambda e^{-\gamma(w-z)}\right)^{2}}+\frac{\left[(y-w) \lambda \gamma e^{-\gamma(w-z)}-\left(k+\lambda e^{-\gamma(w-z)}\right)\right] 2 \lambda \gamma e^{-\gamma(w-z)}}{\left(k+\lambda e^{-\gamma(w-z)}\right)^{3}}
\end{aligned}
$$




$$
J^{\prime \prime}(y, w)=-\frac{(y-w) \lambda \gamma^{2} e^{-\gamma(w-z)}}{\left(k+\lambda e^{-\gamma(w-z)}\right)^{2}}+\frac{2 \lambda \gamma e^{-\gamma(w-z)} J^{\prime}(y, w)}{\left(k+\lambda e^{-\gamma(w-z)}\right)}<0 \text { holds for } w>w^{*}(y)
$$

Proof of lemma 4.

First, we introduce two auxiliary variables:

$$
L\left(w, w_{0}\right) \equiv \frac{1}{k \gamma}\left[\ln \left(k e^{\gamma w}+\lambda\right)-\ln \left(k e^{\gamma w_{0}}+\lambda\right)\right] \quad \text { and } \quad N(y, w) \equiv(y-w) \lambda \gamma e^{-\gamma w}-\left(k+\lambda e^{-\gamma w}\right)
$$

Note that $L\left(w, w_{0}\right)=\left(W(w)-W\left(w_{0}\right)\right)>0$ and $N(y, w)=J_{w}^{\prime}(y, w)\left(k+\lambda e^{-\gamma w}\right)^{2}<0$, because we know that $J_{w}^{\prime}(y, w)<0$ for any valid solution. So the first order condition (10) can be rewritten as:

$$
\beta(y-w)=-(1-\beta) L\left(w, w_{0}\right) N(y, w)
$$

Next, we implicitly differentiate this equation with respect to $w$ and $y$ and rearrange the terms:

$$
\begin{aligned}
& \beta\left(1-\frac{\partial w}{\partial y}\right)=-(1-\beta) L_{w}^{\prime} N \frac{\partial w}{\partial y}-(1-\beta) L\left[N_{y}^{\prime}+N_{w}^{\prime} \frac{\partial w}{\partial y}\right] \\
& \frac{\partial w}{\partial y}\left[\beta-(1-\beta) L_{w}^{\prime} N-(1-\beta) L N_{w}^{\prime}\right]=\beta+(1-\beta) L N_{y}^{\prime}
\end{aligned}
$$

Note that $N_{y}^{\prime}=\lambda \gamma e^{-\gamma w}>0$, so the right-hand side of this equation is positive. To obtain the sign of the square bracket we differentiate $L$ and $N$ with respect to $w$ :

$$
L_{w}^{\prime}=\frac{e^{\gamma w}}{\left(k e^{\gamma w}+\lambda\right)}>0 \quad N_{w}^{\prime}=-\lambda \gamma e^{-\gamma w}-(y-w) \lambda \gamma^{2} e^{-\gamma w}+\lambda \gamma e^{-\gamma w}=-(y-w) \lambda \gamma^{2} e^{-\gamma w}<0
$$

Given that $N<0$ and $L>0$, the square bracket is positive, which proves that $\partial w / \partial y>0$. Next we implicitly differentiate with respect to $w$ and $w_{0}$ :

$$
-\beta \frac{\partial w}{\partial w_{0}}=-(1-\beta)\left[L_{w}^{\prime} \frac{\partial w}{\partial w_{0}}+L_{w_{0}}^{\prime}\right] N-(1-\beta) L N_{w}^{\prime} \frac{\partial w}{\partial w_{0}}
$$

Rearranging terms we get:

$$
\frac{\partial w}{\partial w_{0}}\left[\beta-(1-\beta) L_{w}^{\prime} N-(1-\beta) L N_{w}^{\prime}\right]=(1-\beta) L_{w_{0}}^{\prime} N
$$

We already know that the term in the square bracket is positive, so we need the sign of $L_{w_{0}}^{\prime}$ :

$$
L_{w_{0}}^{\prime}=-\frac{e^{\gamma w_{0}}}{k e^{\gamma w_{0}}+\lambda}<0
$$

Given that $N<0$ for a valid solution, we can see that the right-hand side of this equation is positive, which proves that $\partial w / \partial w_{0}>0$.

\section{A Pseudo-code of the simulation \\ Initialization}

1. Initializing the parameter values and variables of the model

2. Creating $n$ workers and initializing their individual variables (productivities, statuses, wages and transitions of the workers)

3. Creating $n$ firms and initializing their productivities which are randomly drawn from the fixed exponential distribution

\section{Sequence of the events}


4. While $t<T$ ( $T$ is the total number of periods of the run): computing value functions for workers using the expectation parameter $\alpha_{t-1}$ and profit functions for firms: $W_{i t}$ and $J_{i t}$

5. Workers and firms match randomly

5.1 Unemployed workers receive job offers at job finding rate $\lambda$ and accept job offers, since unemployment benefit $z$ equals to zero

a) The worker $i$ and the firm $i$ bargain over the wage: $w_{i t}$

b) The worker's status index is updated to $S_{i t}=1$

c) The transition index is updated to $N_{i t}=1$

d) Worker's productivity level becomes the joint productivity of the worker and the firm: $p_{i t}=y_{i t}$

5.2.1 When current job of the employed worker $i$ is destroyed at probability $\delta$ :

e) The worker's wage becomes zero $w_{i t}=0$

f) The worker's status index is changed to $S_{i t}=0$

g) The worker's transition index is changed to $N_{i t}=0$

h) The worker's productivity level becomes zero $p_{i t}=0$

5.2.2 When current job of the employed worker $i$ is not destroyed at probability $(1-\delta)$ :

1. Employed workers do not receive job offers at probability $(1-\lambda)$ :

All individual variables remain unchanged: $w_{i t}=w_{i t-1}, N_{i t}=0, S_{i t}=1, p_{i t}=p_{i t-1}$

2. Employed workers receive job offers at job finding rate $\lambda$ :

Case 1: The employed worker accepts the new job offer if the joint productivity level with the new firms is higher than the workers' current wage

l) The worker $i$ and the firm $i$ bargain over the wage $w_{i t}$

m) The transition index is updated to $N_{i t}=1$

n) The worker's productivity level becomes the joint productivity of the workers and the firm: $p_{i t}=y_{i t}$

Case 2: If the new firm's productivity is lower than the workers' current wage then the worker stays at the current job and individual variables remain unchanged: $w_{i t}=w_{i, t-1}, N_{i t}=0, S_{i t}=1, p_{i t}=p_{i t-1}$

6. The expectation parameter $\hat{\alpha_{t}}$ is updated:

a) $\hat{\alpha_{t}}=\frac{\sum_{k=1}^{t-1} \sum_{i=1}^{n}\left(\omega_{i k}-\omega_{i k-1}\right)\left(y_{i k}-\omega_{i k-1}\right)}{\sum_{k=1}^{t-1} \sum_{i=1}^{n}\left(y_{i k}-\omega_{i k-1}\right)^{2}}$ if $\exists i$ such that $N_{i t}=1$

b) $\hat{\alpha_{t}}=\alpha_{t-1}$ if for all $i N_{i t}=0$

7. Computing unemployment and employment rates: $u_{t}, e_{t}$.

\begin{tabular}{lccccccc}
\hline $\begin{array}{l}\text { Time trend } \\
\text { Coefficient }\end{array}$ & $t \geq 0$ & $t \geq 50$ & $t \geq 100$ & $t \geq 115$ & $t \geq 130$ & $t \geq 145$ & $t \geq 160$ \\
\hline \hline$\beta=0.4$ & $0.00147^{*}$ & $0.00018^{*}$ & $0.00016^{*}$ & 0.00010 & 0.00003 & 0.00000 & -0.00009 \\
$\beta=0.5$ & $0.00137^{*}$ & 0.00005 & $0.00017^{*}$ & 0.00005 & 0.00005 & 0.00009 & -0.00034 \\
$\beta=0.6$ & $0.00155^{*}$ & $0.00019^{*}$ & $0.00035^{*}$ & $0.00026^{*}$ & $0.00046^{*}$ & $0.00057^{*}$ & 0.00010 \\
\hline \hline
\end{tabular}

Table 9: Regression of the average wage $\bar{w}_{t}$ on time trend $t$, slope coefficients

\section{References}

BALLOT G. (2002): "Modeling the Labor Market as an Evolving Institution: Model Artemis", Journal of Economic Behavior \& Organization, 49(1): 51-77.

BÖHM V., J. WENZELBURGER (1999): "Expectations, Forecasting and Perfect Foresight", Macroeconomic Dynamics, 3: 167-186. 
BRAY M.M., N.E. SAVIN (1986): "Rational Expectations Equilibria, Learning, and Model Specification", Econometrica, 54(5): 1129-1160.

BULLARD J. (1994): "Learning Equilibria", Journal of Economic Theory, 64(2): 468-485.

BURDETT K., D.T. MORTENSEN (1998): "Wage Differentials, Employer Size and Unemployment", International Economic Review, 39(2): 257-273.

CAHUC P., F. POSTEL-VINAY, J.M. ROBIN (2006): "Wage Bargaining with On-the-Job Search: Theory and Evidence", Econometrica, 74(2): 323-364.

CHRISTENSEN B.J., R. LENTZ, D.T. MORTENSEN, G.R. NEUMANN, A. WERWATZ (2005): "On-the-Job Search and the Wage Distribution", Journal of Labor Economics, 23(1): 31-58.

DAWID H., D. DELLI GATTI (2018): "Agent-Based Macroeconomics", In: Hommes C., B.LeBaron (editors). Handbook on Computational Economics, Volume 4: 63-156.

DELLI GATTI D., G. FAGIOLO, M.GALLEGATI, M.RICHIARDI, A.RUSSO (2018): "Agent-Based Models in Economics: A Toolkit", Cambridge University Press.

DOSI G., G. FAGIOLO, A. ROVENTINI (2006): "An Evolutionary Model of Endogenous Business Cycles", Computational Economics, 27: 3-34.

EVANS G.W., S. HONKAPOHJA (1994): "On the Local Stability of Sunspot Equilibria under Adaptive Learning Rules", Journal of Economic Theory, 64: 142-161.

EVANS G.W., S. HONKAPOHJA (1995): "Local Convergence of Recursive Learning to Steady States and Cycles in Stochastic Nonlinear Models", Econometrica, 63(1): 195-206.

EVANS G.W., S. HONKAPOHJA (2001): "Learning and Expectations in Macroeconomics", Princeton University Press, Princeton.

FOURGEAUD C., C. GOURIEROUX, J. PRADEL (1986): "Learning Procedure and Convergence to Rationality", Econometrica, 54(4): 845-868.

FLINN C. (2010): "The Minimum Wage and Labor Market Outcomes", MIT Press, Cambridge MA.

FLINN C., J.MABLI, J.MULLINS (2017): "Firms' Choices of Wage-Setting Protocols in the Presence of Minimum Wages", IRP Discussion Paper, 1434-17.

FREEMAN R. B. (1998): "War of the Models: Which Labor Market Institutions for the 21st Century", Labour Economics, 5: 1-24.

GAFFeO E., M. GAllegati, A. PALESTRINI (2003): "On the Size Distribution of Firms: Additional Evidence from the G7 Countries", Physica A, 324: 117-123.

GAUTIER P.A., C.N.TEULINGS, A.VAN VUUREN (2010): "On-the-Job Search, Mismatch and Efficiency", Review of Economic Studies, 77(1): 245-272.

GEMKOW S., M. NEUGART (2011): "Referral Hiring, Endogenous Social Networks, and Inequality: An Agent-Based Analysis", Journal of Evolutionary Economics, 21: 703-719.

HALL R.E., A.B. KRUEGER (2008): "Wage Formation Between Newly Hired Workers and Employers: Survey Evidence", NBER Working Paper, 14329.

HOMMES C., G. SORGER (1998): "Consistent Expectations Equilibria", Macroeconomic Dynamics, 2: $287-321$.

HOMMES C.H. (2013): "Behavioral Rationality and Heterogeneous Expectations in Complex Economic Systems", Cambridge University Press.

HORNSTEIN A., P. KRUSELL, G.VIOLANTE (2011): "Frictional Wage Dispersion in Search Models: A Quantitative Assessment", American Economic Review, 101(7): 2873-2898.

HORVATH G. (2015): "Network Effects and the Black-White Wage Gap", available at SSRN: https://ssrn.com/abstract $=2660221$

JOLIVET G., F. POSTEL-VINAY, J.M. ROBIN (2006): "The Empirical Content of the Job Search Model: Labor Mobility and Wage Distributions in Europe and the US", European Economic Review, 50: 877-907.

JOVANOVIC B. (1979): "Job Matching and the Theory of Turnover", Journal of Political Economy, 87(5): 972-990. 
LEWKOVICZ Z., D. DOMingue, J.D. KANT (2009): "An Agent-Based Simulation of the French Labour Market: Studying Age Discrimination", In: Edmonds B., N.Gilbert (editors). The 6th Conference of the European Social Simulation Association.

MARCET A., T.J. SARGENT (1989): "Convergence of Least Squares Learning Mechanisms in SelfReferential Linear Stochastic Models", Journal of Economic Theory, 48(2): 337-368.

MARCET A., J.P. NICOLINI (2003): "Recurrent Hyperinflations and Learning", The American Economic Review, 93(5): 1476-1498.

MORTENSEN D.T. (1986): "Job Search and Labor Market Analysis", Handbook of Labor Economics, 2: 849-919.

MORTENSEN D.T. (2003): "Wage Dispersion", The MIT Press, Cambridge.

MUTH J.F. (1961): "Rational Expectations and the Theory of Price Movements ", Econometrica, 29(3): 315-335.

NAGYPAL E. (2008): "Worker Reallocation over the Business Cycle: The Importance of Employerto-Employer Transitions", Working Paper, Northwestern University.

NEAL D., S. ROSEN (2000): "Theories of the Distribution of Earnings", In: Atkinson A., F. Bourguignon (editors). Handbook of Income Distribution, Volume 1: 379-427.

NEUGART M. (2004): "Endogenous Matching Functions: An Agent-Based Computational Approach", Advances in Complex Systems, 7(02): 187-201.

NEUGART M., M.G. RICHIARDI (2018): "Agent-Based Models of the Labor Market", In: Chen S-H., M.Kaboudan, Y-R.Du (editors). Handbook on Computational Economics and Finance, Oxford University Press, Oxford.

PETRONGOLO B., C.A. PISSARIDES (2001): "Looking into the Black Box: A Survey of the Matching Function ", Journal of Economic Literature, 39(2): 390-431.

PISSARIDES C.A. (2000): "Equilibrium Unemployment Theory", The MIT Press, Cambridge.

PISSARIDES C. A. (2009): "The Unemployment Volatility Puzzle: is Wage Stickiness the Answer", Econometrica, 77(5): 1339-1369.

POSTEL-VINAY F., J.M. ROBIN (2002a): "The Distribution of Earnings in an Equilibrium Search Model with State-dependent Offers and Counteroffers", International Economic Review, 43(4): 989-1016.

POSTEL-VINAY F., J.M. ROBIN (2002b): "Equilibrium Wage Dispersion with Worker and Employer Heterogeneity", Econometrica, 70(6): 2295-2350.

RICHIARDI M. (2004): "A Search Model of Unemployment and Firm Dynamics", Advances in Complex Systems, 7(2): 203-221.

RICHIARDI M. (2006): "Toward a Non-Equilibrium Unemployment Theory", Computational Economics, 27: 135-160.

ROTEMBERG J.J. (2017): "Group Learning, Wage Dispersion and Non-stationary Offers", Economica, 84: 365-392.

RUBINSTEIN A.(1982): "Perfect Equilibrium in a Bargaining Model", Econometrica, 50(1): 97-109.

SCHÖNHOFER M. (1999): "Chaotic Learning Equilibria", Journal of Economic Theory, 89: 1-20.

TUINSTRA J., F.O.O. WAGENER (2007): "On Learning Equilibria", Economic Theory, 30: 493513.

ZAHARIEVA A. (2013): "Social Welfare and Wage Inequality in Search Equilibrium with Personal Contacts", Labour Economics, 23: 107-121.

ZAHARIEVA A. (2015): "Social Contacts and Referrals in a Labour Market with On-the-Job Search", Labour Economics 32, 27-43. 